\title{
Birds of a Feather - do Hedge Fund Managers Flock Together?
}

\author{
Marc Gerritzen*, Jens Carsten Jackwerth ${ }^{\dagger}$, and Alberto Plazzi ${ }^{\ddagger}$
}

February 9, 2016

\begin{abstract}
Using a novel data set, we construct a network of hedge fund managers based on past employment. Employment in the same industry and employment in the same firm lead to more similar investment behavior in terms of systematic risk (beta), abnormal performance (alpha), and residual returns, explaining about a quarter of the differences. Employment at the same firm at the same time affects only residual returns. Results are robust to fund and manager level controls, as well as to endogeneity concerns. More connected funds perform better, and prior experience in pension funds and banks aids performance.
\end{abstract}

JEL classification: G11, G20, G23

Keywords: hedge funds, social ties, networks, abnormal performance

\footnotetext{
*University of Konstanz, 78457 Konstanz, Germany, marc.gerritzen@uni-konstanz.de

${ }^{\dagger}$ Corresponding author, University of Konstanz, PO Box 134, 78457 Konstanz, Germany, jens.jackwerth@uni-konstanz.de

¥Università della Svizzera Italiana and Swiss Finance Institute, Via Buffi 13 Lugano, 6900, Switzerland, alberto.plazzi@usi.ch We thank Andrew Karolyi, David Schumacher, Marie-Hélène Broihanne, Christian Ehmann, Alexander Eisele, Anna Slavutskaya, Olga Kolokolova, Alberto Manconi, Joel Peress, Oliver Spalt, Cesare Fracassi, Michela Verardo, Veronika Pool, Denitsa Stefanova, and seminar participants to the 3rd Luxembourg Asset Management Summit, 7th Paris Hedge Fund Conference, Lancaster University, University of Zurich, University of Strasbourg, and the University of St. Gallen for comments. An earlier version of the paper circulated under the title 'Joint Employment Histories of Hedge Fund Managers'. First draft: August 10, 2014.
} 


\section{Introduction}

Much work has been done to study the performance of hedge funds with their intriguing and secretive investment strategies. Traditionally, this has been achieved by looking at factor models in the style of Fung and Hsieh (2004), which are aimed at identifying performance that is left unexplained by exposure to systematic risk factors. ${ }^{1}$ The nuanced message from this voluminous literature is that managerial leeway at hedge funds leaves a large portion of their returns unexplained by standard systematic factors and that the average fund generates significant abnormal (net-of-fee) returns. ${ }^{2}$ However, while this alpha tends to be associated with managerial skill, its analysis has often been reduced to variation due to hedge fund-specific variables such as fees and investment styles, as in Joenvaäärä, Kosowski, and Tolonen (2014), or geography, as in Teo (2009).

In this paper, we contribute to the understanding of hedge funds' investment behavior by looking at social connections that arise among managers sharing a common prior employment history. The current literature largely ignores personal connections between managers and instead treats each hedge fund as being independently structured into systematic components (betas), abnormal return of the manager (alpha), and an idiosyncratic component (residuals). We contend that social ties developed at the prior industry or company employment are natural candidates for explaining differences in hedge fund returns. Managers may arguably learn valuable portable skills and strategies at their former workplace. Moreover, managers with the same background are likely to share a similar mix of exposures to risk factors, which are the result of developing common attitudes towards risk-taking or adopting similar trading strategies. Shared employment careers may also increase social interactions and the exchange of information through social networks. The impact of social ties may not be captured by simple replicating portfolios but rather may show up in the idiosyncratic portion of returns or may generate abnormal performance as managers trade on the same (valuable) signal.

The idea that managers' connections in the form of prior employment matter in the hedge fund industry is neatly illustrated by the case of the Commodity Trading Advisor (CTA) UK segment.

\footnotetext{
${ }^{1}$ Many details surround this literature, such as database biases, econometric issues, and omitted factors, see Joenvaäärä, Kosowski, and Tolonen (2014) for a current survey.

${ }^{2}$ For example, Patton and Ramadorai (2013) report an average adjusted $R^{2}$ of only $32 \%$ when adding intra-month dynamic trading strategies to standard factors (their Table VI).
} 
In 1987, Messrs. Adam, Harding, and Lueck came together to set up their new commodity trading advisor fund, AHL. Before long, the fund was taken over by Man Group and, by 2015, Man AHL has some $\$ 13$ billion in assets. After the takeover in 1994, the original founders created two new CTAs: Harding set up Winton Capital Ltd (\$25 billion, 340 employees); Lueck and Adam set up Aspect Capital Ltd ( $\$ 4.7$ billion, 110 employees). Over the years, several more companies were spun off, such as the CTA Solaise Capital Management with key personal from Winton and Aspect, Kennox Assset Management (which runs long-only equity portfolios) set up by Adam yet again, and Altegris (which also offers mutual funds) with key personal from AHL. The case suggests that industry experience matters for setting up new firms in the same or potentially different investment styles. Also, the knowledge gained at one firm during past employment seems to travel with the managers as they set up new firms. And finally, time spent together at a past employment can create lasting social connections, which can lead to shared ownership at new firms.

Working on the universe of UK hedge funds, we find strong evidence that exposures to systematic risk factors (betas), abnormal performance (alphas), and idiosyncratic shocks (residuals) are more similar for hedge fund managers who are connected to each other through past employment at the same firm or past employment in the same industry. Results are unaffected by including a large number of controls such as fund characteristics and manager-specific details. We are thus first to establish the relevance of such social conducts for the investment decisions of hedge fund managers.

Our study relies on data from mandatory filings that are compiled by management companies domiciled in the UK that run hedge funds. The Financial Conduct Authority (FCA) requires these companies to disclose detailed information on the past employment histories of their key managers. This information includes relevant items such as the name of the former employer, the period of employment, and the role of the employee. The name of the manager and of the hedge fund company is also disclosed, which allows us to match this source with commercial hedge fund databases. The resultant database is much larger and more encompassing than the hand-collected data sets used in the literature, see e.g. Engel, Kerllar, Millio, and Simon (2011). It avails us of a complete historical record of performance, fund characteristics, and work trajectories of the UK hedge fund industry, which is the basis for our analysis. ${ }^{3}$

\footnotetext{
${ }^{3}$ The FCA record starts in 2001 based on a legal requirement for filing as of that year. Some companies voluntarily filed even earlier employment records.
} 
The combined data set allows us to construct the following three measures of social connectedness among UK hedge fund management companies. A first variable, Industry, links two companies whose managers worked in the same industry at some point in time. ${ }^{4}$ Sharing an industry experience may equip managers with a common set of knowledge that subsequently influences their portfolio choice. For a second variable, Firm, a tighter link is established for managers who worked for the same past employer, but at potentially non-overlapping times. Managers who worked for the same company may undertake similar investment decisions that reflect portable strategies they acquired at their former workplace. Finally, a third variable, Overlap, identifies network connections from managers overlapping for a significant time frame (in our setup, at least 24 months) while working for the same employer. This overlap is likely to generate an exchange of information among the people who are part of the same network, which may potentially inform their future investment choices. ${ }^{5}$

Examining the work trajectories of UK hedge fund managers through our definitions of social ties reveals a highly interconnected world. In fact, the great majority of funds in our dataset share connections of some sort. We utilize this information to ask whether social ties and work experience can explain similarities in hedge fund returns. Given the high degree of complexity in hedge funds trading, we test for the impact of employment history separately along the three dimensions of hedge fund performance, namely abnormal performance (alpha), systemic risk factors (beta), and idiosyncratic shocks (residuals). To that end, we resort to the widely used Fung and Hsieh (2004) 7-factor model, which we estimate at the fund level. For each pair of funds, we then compute the average absolute distance in their factor exposures $(\Delta \beta)$, the time-series average in the absolute difference in residuals $(\Delta \epsilon)$, and the absolute difference in abnormal returns $(\Delta \alpha)$. These three distances serve as dependent variables for our analysis. ${ }^{6}$

We document that social connections, in particular prior Industry and Firm experience, explain a significant fraction of cross-sectional differences across the three dimensions of returns. The corresponding coefficients are not only statistically but also economically large, as they imply that the distance in alpha for any fund pair is $0.25 \%$ per month closer for connected funds, or

\footnotetext{
${ }^{4}$ The FCA record only requires firms in the financial industry to file. As a result, the 'industries' are fields within the financial sector such as banking.

${ }^{5}$ Note that the variables are nested in that overlapping managers always worked for the same Firm. Managers at the same Firm always share the same Industry.

${ }^{6}$ Compare Fracassi (2015) for a related two-stage estimation of network effects on returns in a corporate finance setting.
} 
about $3 \%$ per year. For the distance in exposure to risk factors, connected funds have each factor exposure reduced by 0.27 on average. The idiosyncratic component, $\Delta \epsilon$, is even reduced by $0.62 \%$ on average, or more than $7 \%$ per year. The effect of overlapping times spent at a joint former employer (Overlap) does not affect $\Delta \alpha$ and $\Delta \beta$ but significantly impacts $\Delta \epsilon$. The idiosyncratic risk taking seems to depend more on social networks and personal interaction rather than industry and firm effects.

These results are robust to the inclusion of standard controls such as the distances in funds' size, age, and compensation structures, which may indirectly capture the effect of common work trajectories. We also include a style dummy, which guarantees that our findings do not merely originate from correlation between investment styles and employment opportunities or from funds relying on the same style-specific trading.

In various ways, we try to rule out the possibility that our findings simply reflect fund characteristics. First, we estimate our regression model across pairs of funds with similar strategies or size and ask whether the effects line up with expected differences in social ties. We find that an overlap in prior employment is more relevant when focusing on investment strategies for which information sharing is likely to play a crucial role, such as Event-Driven, Convertible Arbitrage, and Merger Arbitrage. Also, social ties tend to be more important for pairs of small funds, defined as funds with below median number of employees, for which key executives influence the fund strategy more. Taken together, these cross-sectional patterns lend further support to the claim that our measures capture network-related dynamics, rather than individual characteristics.

Employment history is potentially correlated with unobserved manager characteristics, such as gender, age, education, or skill. ${ }^{7}$ We control for gender and age to proxy for personal attributes such as risk-aversion and career concerns. ${ }^{8}$ We also check that network effects are based on employment histories and not simply driven by physical proximity, which also would facilitate exchange of information with other managers. Hong, Kubik, and Stein (2005) show that managers in the same city display correlated trades. Our measure of physical proximity is a dummy, which indicates if management companies are headquartered in the same postcode. While physical proximity enters with a significant coefficient, it does not absorb the effect of our measures of social ties, which

\footnotetext{
${ }^{7}$ Grinblatt, Keloharju, and Linnainmaa (2012) find that investors with higher skill (measured by IQ) outperform their peers.

${ }^{8}$ Unfortunately, data on schooling or other personal details are not available in our data.
} 
suggests that they capture different information channels. Manager characteristics turn out to have a very limited role in explaining distances in the components of returns, after controlling for fund characteristics.

Controlling for manager skill is more difficult. To do so, we first resort to a measure capturing the strength of the hedge fund labor market in the year the manager entered the fund, Hiring Climate. Hiring Climate is motivated by the evidence in Deuskar, Pollet, Wang, and Zheng (2011) that managers moving from the mutual fund industry to the hedge fund industry tend to do so when the latter is in a boom period. Importantly, these fund managers had poor performance track records in the mutual fund and continue to underperform in the hedge fund. This fact is consistent with hedge funds lowering their hiring standards during periods of rapid hedge fund growth, when the short term supply of managers is inelastic. We compute a manager's Hiring Climate as the number of people being newly employed minus people leaving the financial industry during the month when the manager was hired at the hedge fund. A management company's Hiring Climate is the average over all its managers. It proxies for average manager skill within a company. We use Hiring Climate either as an additional control or an instrumental variable. Alternatively, for ex-hedge fund managers, we compute their past alpha. The assumption here is that personal skills would induce persistence in performance across funds run by the same manager in different companies. Notwithstanding the inclusion of these variables, the economic and statistical significance of social ties from prior employment remains intact. We take this evidence as supportive of a direct effect of social ties on managers' decisions that goes beyond personal characteristics and innate skills.

Finally, we gauge the economic significance of hedge funds' employment background for the performance of individual funds, rather than pairs. Namely, we ask whether sorting funds on managers' prior industry training is associated with significant dispersion in abnormal performance. We find that industry experience of a manager significantly influences future alpha with managers from pension funds and banks outperforming and managers from investment management underperforming. We also explore the economic gains from loading on connected funds through a bootstrap exercise. There, we randomly group funds into portfolios and then sort these portfolios based on the degree of industry connectedness. We document that the decile of most connected funds outperforms the decile of least connected funds by a significantly positive abnormal return of about 60 basis points 
per month. Overall, the results lend further support to the claim that managers' connections have ultimately beneficial effects on performance, consistent with Pool, Stoffman, and Yonker (2015).

The remainder of the paper proceeds as follows. Section 2 relates our paper to the existing literature on social interactions in financial markets. Section 3 describes the data set and the construction of our measures of connectedness. Here, we also detail the dependent variables and their construction via auxiliary factor model regressions. Section 4 outlines our estimation strategy and presents the empirical results linking hedge fund performance to social connections via employment histories. Further results addressing managerial characteristics and endogeneity concerns follow in Section 5. Section 6 investigates the economic significance of our results. We report robustness results in Section 7 and conclude in Section 8.

\section{Related literature}

The paper contributes to the surging literature on the impact of social connections on investment and managerial decisions. A number of studies focus on retail investors and money managers. For households, Hong, Kubik, and Stein (2004) find that more socially interactive investors tend to participate more in the stock market, and the impact of sociability is higher in states with higher levels of participation. For mutual fund managers, the work of Hong, Kubik, and Stein (2005) and Pool, Stoffman, and Yonker (2015) are the closest to the spirit of our paper. Hong, Kubik, and Stein (2005) show that holdings and trades of mutual fund managers who work in the same city are closer to their peers. They interpret this evidence as a direct consequence of interpersonal word of mouth exchange of ideas among the agents. Pool, Stoffman, and Yonker (2015) find significant overlap in the holdings of managers who live in the same neighborhood and convincingly demonstrate that these effects arise from social interactions rather than similarities in preferences. They further show that the transmission of information through the network of neighboring managers generates abnormal performance. Here they investigate mutual fund managers who invest into the same company. Mutual fund managers who are are connected to the company CEO through educational background outperform unconnected managers (Cohen, Frazzini, and Malloy (2008)) and are more likely to vote against shareholder-initiated proposals to limit executive compensation (Butler and Gurun (2012)). We expand the evidence in these studies by documenting that social ties in the 
form of prior employment trajectories are first-order determinants for another class of institutional investors, namely hedge funds.

For hedge funds, the role of geographical distance on performance is explored by Teo (2009). He shows that funds whose physical presence is closest to the investment region outperform their peers, which he attributes to local information advantages. Information on hedge fund managers' prior employment is examined in Deuskar, Pollet, Wang, and Zheng (2011) for a subset of managers who switch from the mutual fund industry. These managers are found to exhibit persistent underperformance, and their hiring is concentrated in periods of expansion of the hedge fund industry. Also related is Papageorgiou, Parwada, and Tan (2011), who look at the effect of past work experience on performance. We add to this literature by documenting that social ties among hedge fund managers induce similarity in their returns. We are also the first to measure the economic significance of these ties by showing that portfolios of funds that load on connected hedge managers on average deliver higher performance than unconnected funds.

A large body of the literature documents the pervasive importance of director and CEO networks. Hwang and Kim (2009) show that board independence is substantially weaker when considering social ties among the board members that facilitate personal connections. Cohen, Frazzini, and Malloy (2010) document that analysts who possess educational links to company senior managers outperform their peers in terms of precision of stock recommendations. Corporate policy and investment are found to be more similar for firms where the key employees share social ties, Fracassi (2015). Having a large network increases CEO compensation, as evidenced by Engelberg, Gao, and Parsons (2013). Educational and prior employment linkages between company and bank managers reduce the interest rate charged by syndicates (Engelberg, Gao, and Parsons (2012)), while those between directors and senior executives at acquiring and target firms instead tend to lower overall value creation (Ishii and Xuan (2014)). Our evidence suggests that social connections between hedge fund managers and corporate executives may also be an interesting venue of analysis.

Finally, our paper naturally adds to the discussion on the determinants of hedge fund returns. We demonstrate that an economically important fraction of the cross-sectional distribution of abnormal performance and idiosyncratic risk can be traced to social connections, which appear not to be captured by exposures to commonly used systematic risk factors. 


\section{Data and Variables Construction}

Our analysis requires the intersection of three different data sources: hedge fund databases, managers' employment histories, and industry classification of prior employers. First, we gather information on hedge fund performance and attributes. Existing studies on hedge funds mainly focus on few databases, the most commonly used being Lipper TASS, HFR, and Morningstar. Recently, Joenvaäärä, Kosowski, and Tolonen (2014) provide compelling evidence that individual hedge fund databases are not representative of the industry as a whole. They show that differences among databases may induce survivorship biases and alter the inference on the determinants of hedge fund performance, which is the focus of our study. For these reasons, we rely on a comprehensive dataset that is obtained by combining six major hedge fund databases, namely Morningstar, Eurekahedge, BarclayHedge, HFR, TASS, and CISDM. The merging procedure and filters follow Hodder, Jackwerth, and Kolokolova (2014) and are similar to Joenvaäärä, Kosowski, and Tolonen (2014). ${ }^{9}$ We restrict to funds which report in USD. ${ }^{10}$ The data consists of monthly information on 21,547 hedge funds (organized in 9,147 management companies) from January 1977 to December 2012, of which 16,374 are dead funds and 5,173 are live funds. Keeping the dead funds addresses potential survivorship bias. The backfill bias is due to the possibility to list older (and typically higher) returns in the database at the time of joining the database. If performance is correlated with prior work experience, as we demonstrate later, this practice would induce a selection bias and lead us to over-estimate the effect of social ties. We follow prior studies (see e.g. Kosowski, Naik, and Teo (2007) and Teo (2009)) and remove the initial 12 months of each fund's return data history.

Next, we retrieve information about the employment histories of hedge fund employees from the Financial Services Register (FSR) which is compiled by the Financial Conduct Authority (FCA). The FCA regulates insurance, investment, and banking companies that are domiciled in the UK ('onshore'). Importantly, the FSR includes the normally secretive management companies that control hedge funds. The Financial Services and Markets Act 2000, which came into force on

\footnotetext{
${ }^{9}$ Specifically, we merge the databases on the names of the hedge funds' managing companies. We remove duplicates and different share classes of the same fund within each company by grouping the funds if their return correlations are above 0.99. Within each group, we keep the fund with the longest time series of returns.

${ }^{10}$ The great majority of managing companies have multiple share classes for the same strategy which are denominated in various currencies. We opt for the class denominated in USD as this is by far the most common.
} 
December 1, 2001, requires all those companies to report detailed information on current and past employment of their key employees. The FCA makes the resultant database publicly available with full disclosure of the employee name. ${ }^{11}$

Using the FSR has clear advantages with respect to other available sources. The fact that the FCA requires reporting rather than voluntary disclosure increases the completeness and accuracy of the FSR information, which is comparable to existing databases on US executives such as the widely used Boardex. ${ }^{12}$ The resulting sample should be devoid of any selection bias and is survivorshipbias free as the FSR also keeps track of dead companies. As the record is only available for UK companies and is only reliable as of 2002, we limit ourselves to the years 2002 to 2012 and to UKdomiciled management companies. Note that the records exist only at the level of the management company and not the individual hedge fund.

Our analysis utilizes the following information: the hedge fund management company name; the employee's name and a numeric ID; the full employment history with names of former employers (FCA-registered only) with entry and exit dates; an identifier (the Controlled Function (CF) Code that specifies the employee's role in the management company. The CF Code is of special importance to us as it identifies the various regulated functions within the management companies. The Financial Services and Markets Act lists a total of sixteen such functions for UK firms that are ranked based on their significant influence on the activity. ${ }^{13}$ We later use this code to identify key hedge fund employees who form our network.

We match the FSR and the combined hedge fund dataset based on the management company name. For further consideration, we require a fund to report returns for at least 24 months. The resulting sample comprises 685 UK-domiciled companies managing 2,930 distinct hedge funds (788 live and 2,142 dead) from January 2002 to December 2012. Consistent with the findings in

\footnotetext{
${ }^{11}$ The FCA was formerly known as Financial Services Authority (FSA). The FSA was created in 1997 with responsibility for banking supervision, listing authority, and investment services regulation. With the Financial Services and Markets Act 2000 , it started to exercise statutory powers to regulate the financial services industry. In the wake of the financial crisis of 2007-2008, the Financial Services Act of 2012 set out a new system for regulating financial services in order to protect and improve the UKs economy, and the FSA was abolished with effect from April 1, 2013. Its responsibilities were then split between two new agencies (the Prudential Regulation Authority and the Financial Conduct Authority) and the Bank of England. The FCA continues to maintain the FSR originally developed by the FSA. For the purpose of measuring the effect of social ties in the hedge fund industry, it is reasonable to consider the introduction of the act as an exogenous regulatory change.

${ }^{12}$ Reporting to FSA is not merely a formality as companies that fail to report for approval of a key employee may be subject to FSA investigations and ultimately to fines.

${ }^{13}$ See the full list at http://www.fsa.gov.uk/doing/regulated/approved/persons/functions. A detailed description of each CF code function can be found in the CFA handbook, http://fshandbook.info/FS/html/handbook.
} 
Joenvaäärä, Kosowski, and Tolonen (2014), we find that only 45 funds are jointly reporting to all databases and that nearly half of them $(1,545)$ report to only one database.

In addition to net-of-fee returns, the hedge fund data includes a wealth of fund-level characteristics, such as management fee, performance fee, and investment style. It also contains a leverage indicator and the amount of assets under management, albeit for a much smaller set of funds. We complement this information with the number of employees. This number serves as an alternative measure of company size, as it is available in the FSR for the large majority of companies.

Finally, we classify FSR former employers into 11 industries within the financial services sector. We contend that managers acquire distinct skills in these different sectors: Banking, Brokerage firms, Consultancy firms, Hedge Funds, Insurance companies, Investment Banks, Investment Management, Mutual Funds, Pension Funds, Private Equity, and the residual group Other. The classification is obtained by matching the company name with the Registrar of Companies that is maintained by the UK Companies House database and by manual verification. ${ }^{14}$

\subsection{Connection Measures}

Our main goal is to capture the effect of past work experience on the investment decisions of hedge fund managers. We define three measures of social ties that capture different facets of hedge fund managers' work trajectories:

i) Industry: The variable equals one if two employees have been working for a company operating in the same industry at some, potentially different, point in time for a minimum of 12 months for each manager.

ii) Firm: The variable equals one if two employees have been working for the same company at some, potentially different, point in time for a minimum of 12 months for each manager.

iii) Overlap: The variable equals one if two employees have been working for the same company during the same period of at least 24 months.

\footnotetext{
${ }^{14}$ Data on live companies are readily obtainable from http://www.companieshouse.gov.uk/. Hedge funds we can identify easily through our own merged database. Mutual funds we identify in the Morningstar database. Finally, we classify the remaining firms by manual web-based investigation. Investment management firms are investment advisers, which cannot be clearly subsumed under private equity, mutual fund, or hedge fund.
} 
We face two challenges in constructing these variables since our data document employment at the management company and not the individual hedge fund level. First, we focus on the senior managers of the management company, who determine the general strategy at all hedge funds owned: Director ( $\mathrm{CF}$ code 1), Chief Executive ( $\mathrm{CF}$ code 3), or Partner (CF code 4). Our choice is supported by our hedge fund data from which we know the names for a subset of 139 managers. These are mostly classified as either CF code 1 (40\% of times), CF code 3 (16\% of times), or CF code 4 (23\% of times). Henceforth, we refer to any such employee as a (hedge fund) 'manager.'

Second, we construct all our variables at the management company level. Such data limitation should work against our empirical tests as we potentially classify unconnected funds as linked, implying that our empirical results should be considered as a lower bound for the relevance of social connections. Accordingly, we define two management companies as socially connected if at least two of their employees share a social tie. That is, Overlap equals 1 for the pair of funds $(i, j)$ if an employee of management company of fund $i$ worked at the same firm as an employee of management company of fund $j$ during the same period of at least 24 months, and similarly for Industry and Firm. ${ }^{15}$

We realize that these variables reflect distinct channels leading to similar investment choices. On the one hand, hedge fund managers may acquire portable skills and expertise at a former employer or industry. For example, two managers who both worked at Goldman Sachs are likely to exhibit a similar propensity toward managing fixed income products due to the training in fixed income they received in the workplace. Similarly, former employees who worked in the life insurance industry may develop an attitude toward risk that is different than that of employees in the banking sector. On the other hand, employees are likely to establish personal interactions through mutual work experience. We contend that these connections are presumably stronger at the firm rather than the industry level and for employees who overlapped in their working experience. To the extent that managers continue to discuss ideas with their former colleagues, as evidenced by Simon, Millo, Kellard, and Engel (2012), these ties may lead to the exchange of information and induce correlated strategies. In what follows, we refer to the sharing of prior employment alternatively as social ties or networks, keeping in mind that the underlying economic mechanisms may be quite different.

\footnotetext{
${ }^{15}$ To construct the network measures, we take into account all prior work experiences an employee had during the relevant network period. The median hedge fund employees worked in one prior industry and for two distinct employers.
} 


\subsection{Dependent Variables}

We ask whether the investment decisions of hedge funds whose managers are socially connected are more similar vis-à-vis those of unconnected funds. Social ties could impact hedge fund returns through abnormal performance (alpha), systematic risk exposures (beta), and idiosyncratic risk (residuals). Following Kosowski, Naik, and Teo (2007), Deuskar, Pollet, Wang, and Zheng (2011), and others, we resort for the decomposition of hedge fund returns to the 7-factor model of Fung and Hsieh (2004). ${ }^{16}$ For each hedge fund $i$ in our sample we estimate the model

$$
x r_{i, t}=\alpha_{i}+\beta_{i}^{\prime} F_{t}+\epsilon_{i, t}
$$

where $x r_{i, t}$ denotes hedge fund $i$ net-of-fees return in excess of the risk free rate in month $t, F_{t}$ collects the contemporaneous factor returns, $\alpha_{i}$ measures the fund abnormal performance, and $\epsilon_{i, t}$ is the mean-zero idiosyncratic error term. We standardize each of the factors to exhibit unit standard deviation.

We construct three dependent variables that capture distances in the three components of hedge fund returns. For abnormal performance (alpha), we measure the absolute distance in the estimated intercept from equation (1):

$$
\Delta \alpha_{i, j} \equiv\left|\alpha_{i}-\alpha_{j}\right|
$$

For the systematic risk exposures (beta), we measure the average absolute distances in the funds' estimated $\beta \mathrm{s}$ :

$$
\Delta \beta_{i, j} \equiv(1 / 7) \sum_{k=1}^{7}\left|\beta_{i, k}-\beta_{j, k}\right| .
$$

Finally, for idiosyncratic risk (residuals), we measure the average absolute difference of the estimated residuals:

$$
\Delta \epsilon_{i, j} \equiv(1 / T) \sum_{t=1}^{T}\left|\epsilon_{i, t}-\epsilon_{j, t}\right| .
$$

The smaller any distance between two funds is, the more similar are their investment strategies in terms of exposures to systematic risks $(\Delta \beta)$, idiosyncratic risk $(\Delta \epsilon)$, and abnormal performance

\footnotetext{
${ }^{16}$ The factors are: the excess return of the S\&P 500; a size factor as the difference between the Russell 2000 and the S\&P 500 indexes; the change in the 10-year treasury constant maturity yield; the change in the credit spread of Moody's BAA bond over the 10-year Treasury bond; and the excess return on portfolios of lookback straddle options on currencies, commodities, and long-term bonds. We obtain the factors from https://faculty.fuqua.duke.edu/ dah7/HFRFData.htm.
} 
$(\Delta \alpha)$. In Section 7 , we show that using alternative factor models does not markedly alter our findings.

\subsection{Dataset Construction and Filters}

To investigate whether social connections make two funds $i$ and $j$ behave more similarly, we relate similarities in hedge fund returns $(\Delta \beta, \Delta \epsilon$, and $\Delta \alpha)$ to measures of manager connectedness (Overlap, Firm, and Industry). However, unlike other studies that look at the effect of social ties on holdings (Pool, Stoffman, and Yonker (2015)) or corporate outcomes (Fracassi (2015)), our dependent variables are not directly observable but need to be estimated over a period of time.

We tackle this issue by resorting to a 'wave' structure. In each wave, we estimate the performance model during a three-year 'evaluation' period and use the previous six-year 'network' period to construct our measures of social ties. We begin our analysis in 2002, when FSR reporting became mandatory, thereby obtaining 3 evaluation waves starting in January of 2008, 2009, and 2010. To fix ideas, for the first 'wave' we estimate the auxiliary factor model on 2008-2010 return data and create our explanatory variables using data from 2002 to 2007 included. We next move our evaluation and network period forward by one, and then two, years. ${ }^{17}$ Given the length of our data, the one-year gap between evaluation periods strikes a balance between sample availability and overlap in the estimation period. This estimation procedure approximates a dynamic panel, which would obtain by re-estimating our dependent variable every month. To make sure that the manager does not exit the evaluation period too early, thereby potentially diluting the proximity with other connected funds, we require the managers to be present in the same company for at least 24 months in the evaluation period. Also, funds need at least 24 time-series observations during the evaluation period to accurately estimate the factor model.

\section{Social Ties and Hedge Fund Returns}

After applying the filters described above, the final database consists of 1,483 hedge funds which are run by 443 distinct management companies, or about 3 funds per company. Collectively, we

\footnotetext{
${ }^{17}$ We move forward both the beginning and the ending dates. This guarantees that the network does not get increasingly dense, as 'old' social ties are severed once they exit a given six-year window.
} 
identify a total of 1,799 managers who are employed at any time in a UK management company during our 2002-2012 time span. According to our definition of connectedness, we identify 1,138 managers who are linked to at least one other individual through past employment in the same (finance) industry. Thus, about $37 \%$ of the managers in the sample are 'outsiders' as they joined the hedge fund industry without prior experience in the finance sector.

[Table 1 about here]

As a prelude to our analysis, Panel A of Table 1 collects descriptive statistics at the fund level across the three waves. The first three rows collect statistics for the three measures of social ties: Industry, Firm, and Overlap. A fund is connected with another fund if there exists at least one connection in any of the three waves. About $56 \%$ of all hedge funds are connected through Industry, counting only connections to other management companies and excluding hedge funds at the same management company. The percentages of connections for work experience at the same firm, Firm, and during the same time, Overlap, are $41 \%$ and $27 \%$. These numbers reinforce the view that social ties are not confined to a select few funds.

For the average fund in the sample, the monthly abnormal return, $\alpha$, is about $0.14 \%$. There is, however, considerable dispersion in $\alpha$ ranging from $-6 \%$ to as high as $13 \%$ per month. The adjusted $R^{2}$ of the auxiliary regressions averages at $48 \%$, but it too varies in a wide range from $2 \%$ to $99 \%$.

The last six rows of Panel A report fund characteristics, which we use as control variables. These are: Age, measured by the number of months the fund appears in the hedge fund databases; EmpSize, the number of total employees of the management company (from the FSA); management fee $(M g m t F e e)$, in percent; performance fee (PerfFee), in percent; a Leverage dummy, which equals one if the fund utilizes positive leverage, and zero otherwise; and assets under management $(A u M)$, in million USD. The median fund has been present in the database for about 60 months, has 18 employees (including all CF-codes), and utilizes compensation schemes in the form of a management fee $(2 \%)$ and, especially, a performance-based fee $(20 \%)$. About $31 \%$ of the funds make use of some degree of leverage in their operations, conditional on this variable being present (exists for only $57 \%$ of funds). Finally, the median fund has 106 million USD of assets under management, but the distribution is highly skewed. It is important to control for these variables 
as Joenvaäärä, Kosowski, and Tolonen (2014) report a significant relation between monthly alphas from the 7-factor Fung and Hsieh (2004) model and most of these characteristics. ${ }^{18}$

The second block in Panel A breaks down the distribution of funds by style, sorted in descending order among the six most numerous categories. Our sample mimics quite closely the industry in general as outlined in Lo (2007), with the great majority of the funds being classified as Equity Long/Short (about 45\%) and Global Macro (about 16\%). Overall, the funds in our sample are active in twelve distinct styles, plus a residual 'Other' group.

Panel B of Table 1 reports descriptive statistics at the fund-pair level that will be the basis for our econometric investigation. Since our measures of social connectedness are constructed at the management company level, we exclude from the analysis pairs of funds that belong to the same company. Hence, a unit is a pair of funds that are run by two distinct companies. The first block of rows collects statistics for our three dependent variables $(\Delta \alpha, \Delta \beta, \Delta \epsilon)$, which are winsorized at the top and bottom $0.5 \%$ to reduce the influence of outliers. We observe an economically very large dispersion in abnormal performance. The average $\Delta \alpha$ is about $0.88 \%$ per month, or about $10.50 \%$ in annual terms. The standard deviation is comparable at $0.85 \%$, and the distance in $\alpha$ is as large as $5 \%$ monthly. Considering that the average absolute excess return in the evaluation period is $2.92 \%$, these figures underscore a large degree of cross-sectional heterogeneity. ${ }^{19}$ The average distance in $\beta$ between any two funds is 1.149. The large value is due to our factor scaling - as the Fung and Hsieh (2004) factors differ widely in standard deviation, we normalized them to have unit variance. There is, however, significant variation in this distance too, ranging from 0.19 to as high as 5.20 . Finally, $\Delta \epsilon$ averages $2.98 \%$ with a standard deviation of $2.00 \%$. The second three rows focus on the measures of connectedness (Industry, Firm, and Overlap), which are defined at the management company level, see Section 3.1. For about $22 \%$ of all possible fund pairs we observe a connection through Industry. This is the most common linkage. About $1.3 \%$ of the pairs share a former employer (Firm), while nearly $0.5 \%$ are connected via an overlap in the work experience of their managers (Overlap). While these numbers sound low, a third of all managers have at least one Overlap connection and more than half have at least one Industry connection. So managers

\footnotetext{
18 Joenvaäärä, Kosowski, and Tolonen (2014) do not find a significant link between alphas and share restrictions (lockup period, redemption period, and redemption notice period) in their combined hedge fund database. Since data on these variables is also sparse, we do not include them in the analysis.

${ }^{19}$ The average $\Delta \alpha$ for funds in the same style is comparable at $0.85 \%$ per month. Hence, the variability is not just originating from comparing funds across different styles.
} 
are well embedded in social networks, just not everybody with everybody else.

Before turning to the results, we note that the distribution of prior employers is not dominated by any single industry or company. Panel A of Figure A1 in the appendix reports the distribution of the prior industry employment. Panel B shows the histogram of the number of managers that belong to the ten largest former employers. Together they are associated with $8 \%$ of all prior employments. Managers predominantly worked in investment management and at hedge funds, and a total of 224 managers belong to the top-5 prior employers. ${ }^{20}$ Finally, Table A1 in the appendix contrasts the average and median fund characteristics in our sample with those from the full data set. As we can see, the differences are small and insignificant along many dimensions, which suggests that our UK funds are quite representative of the universe of hedge funds used in prior studies.

\subsection{Methodology}

We estimate the following pooled panel regression relating the distance in performance measures $(\Delta \beta, \Delta \epsilon, \Delta \alpha)$ to the network variables (Industry, Firm, Overlap), cross-sectional controls, and style and time dummies:

$$
\begin{aligned}
& \Delta y_{i j, t \rightarrow t+2}=\text { const }+\beta_{1} \text { Industry }_{i j, t-1}+\beta_{2} \text { Pedigree }_{i j, t-1}+\beta_{3} \text { Overlap }_{i j, t-1}+\gamma^{\prime} X_{i j, t-1}+ \\
& \xi \text { StyleDummy }+\psi \text { TimeDummy }+u_{i j, t \rightarrow t+2}
\end{aligned}
$$

where $\Delta y$ denotes alternatively $\Delta \beta, \Delta \epsilon$, or $\Delta \alpha$. The subscripts highlight the fact that the dependent variable is constructed for each pair of funds $i$ and $j$ using data from year $t$ to year $t+2$ (the 'evaluation' period) while the explanatory variables are measured using information up to the end of year $t-1$, with $t$ being 2008, 2009, and 2010, respectively, accounting for the three waves. ${ }^{21}$ Thus, our framework is predictive (in-sample) in the sense that it amounts to asking how much of the future distance in the performance measures of any two funds can be captured by today's information. The style dummy is one if both funds follow the same style and zero otherwise.

\footnotetext{
${ }^{20}$ These are: Martin Currie Investment Management Ltd, Cheyne Capital Management (UK) LLP, Brevan Howard Asset Management LLP, Goldman Sachs International, and JPMorgan Chase Bank, N.A.

${ }^{21}$ That is, we estimate a pooled version of equation (5) where observations across difference 'waves' are stacked, and coefficients are assumed to be constant across waves.
} 
This implies that our results should be interpreted as capturing deviations from the common style. Standard errors are clustered at the fund-pair level, as in Pool, Stoffman, and Yonker (2015). We expect negative coefficients for the network measures, consistent with the view that socially connected managers exhibit more similar asset allocation and trading decisions.

\subsection{Results}

Do social networks influence investment behavior? We start by assessing the impact on differences in abnormal returns, $\Delta \alpha$. Results are collected in Table 2, Panel A. In model (1), we only include the network variables plus style and time dummies. Sharing a common industry background and employer has the expected negative sign on the distance in alphas. The loadings on Industry and Firm are -0.152 and -0.098 , respectively, both significant at the $1 \%$ confidence level. In stark contrast to these findings is the evidence that an overlap in former mutual work experience is not accompanied by a significant reduction in $\Delta \alpha$. The coefficient on Overlap is positive but small at 0.032 and insignificant. The style dummy enters negatively (0.038 and a $t$-statistic of -1.9$)$, which is expected as funds of same style should have more similar investment behavior.

[Table 2 about here]

We next augment the regression by including fund-level controls in model (2). If connected managers tend to establish or join funds with similar fund structures (say, because they develop similar attitudes toward performance-based compensation schemes), including the controls potentially captures part of the overall effect of managers' ties. Consistent with this argument, we see that the coefficients of Industry and Firm decrease in absolute value to -0.104 and -0.093 . However, both of the effects remain significant, with $t$-statistics of around 5 . The coefficient on Overlap is again positive and insignificant. From the controls, size (as proxied by the log of the average number of employees) and (log average) age stand out as important determinants, consistent with Joenvaäärä, Kosowski, and Tolonen (2014). Both controls have negative coefficients, leading to more similar alpha for larger and older firms. As the controls remain stable throughout most regression models, we only discuss them when needed. 
We noticed that about a third of all managers are not part of a network as they do not have a prior employer who is regulated by the FCA. We label these managers 'outsiders.' Our results could be driven by similarities in managers who worked for a finance-related firm compared to these 'outsiders.' To address this issue, we restrict the sample in model (3) to pairs of managers with prior employment in the finance sector. As expected, the importance of Industry is now reduced, with the coefficient being halved at -0.048 , but still significant at the $5 \%$ level. In contrast, the impact of Firm is comparable to the full sample figure, with a significant and large negative estimate of -0.097 .

In Panel B of Table 2, we turn our attention to the regression for the distance in systematic risk exposures, $\Delta \beta$. In the specification without controls in model (1), the estimated loading on Industry is again negative at -0.141 and strongly significant with a $t$-statistic of -5.47 . A common Firm has a comparably negative impact of -0.130 , which is also significant at the $1 \%$ level. Overlap is again insignificant. The inclusion of control variables in model (2) decreases somewhat the coefficients of Firm and Industry to -0.098 and -0.107 . Both remain highly significant, suggesting that social connections capture similarities in managers' systematic risk exposures that are not subsumed by differences in funds' characteristics. When excluding 'outsiders' in model (3), the loading on Firm changes slightly to -0.104 , while the coefficient on Industry decreases to -0.041 and loses significance.

Finally, Panel $\mathrm{C}$ of Table 2 presents the estimates for the regression of $\Delta \epsilon$. Without controls, we find for model (1) that the coefficients for Industry and Firm are negative at -0.386 and -0.238 and highly significant. Interestingly, the coefficient on Overlap is also negative, relatively large at -0.140 , and significant at the $1 \%$ level. Thus, network connections originating from a common work experience seem to play a role in explaining idiosyncratic risk. This is consistent with 'word-of-mouth' transmission of information that propagates through the network of managers who know each other personally. Including control variables in model (2) decreases the coefficients on Industry and Firm, while leaving the results strongly significant. For Overlap, the coefficient is almost unchanged at -0.139 and significant. Excluding 'outsiders' in model (3) leaves Firm largely unaffected and reduces the effect of Industry. Overlap is now larger at -0.155 and again significant at the $1 \%$ level. This suggests that word-of-mouth effects, which can arise from close 
relationships established in the workplace, seem to affect the idiosyncratic return component of hedge fund managers.

We show so far that social ties in the hedge fund industry play a relevant role in explaining differences among fund returns through differences in alpha, beta, and residuals. Sharing a common Industry and Firm has by far the most robust and significant effect. These effects are also economically quite large, which we document by comparing the joint effect of having worked for the same Firm (and thus in the same Industry) from model (1) in Table 2 to the averages of our differences in performance measures from Panel B of Table 1. For monthly abnormal returns $(\Delta \alpha)$, social ties reduce the average of 0.88 by 0.25 . In annual terms, this reduction (of $28 \%$ ) translates into a large $3 \%$ figure. The average factor loading $(\Delta \beta)$ of 1.15 is reduced by 0.27 ( $23 \%$ reduction) and the average residual $(\Delta \epsilon)$ of 2.98 by 0.62 (21\% reduction). Social ties thus account for about a quarter of the cross-sectional differences in performance measures. In contrast, network connections that arise from Overlap in the work experience appear to explain only the idiosyncratic part of returns, which may be capturing dynamic trading based on the sharing of ideas through the network. We revisit the discussion about the economic significance of social ties in Section 6 .

\subsection{Subsample Analysis}

The universe of hedge funds is characterized by a wide spectrum of investment strategies, both in terms of asset classes and types of financial products. A natural question that arises is whether cross-sectional differences in these strategies impact our findings on the influence of social ties on investment decisions.

We begin by grouping hedge funds by broad investment strategies based on the classification in Agarwal, Daniel, and Naik (2009). We then estimate equation (5) separately for pairs of funds belonging to the three largest strategies, namely, Security Selection (including Equity Long and Equity Long/Short, about 23\% of all pairs), Directional Traders (including Emerging Markets and Global Macro, about 1.5\% of all pairs), and Multiprocess and Relative Value (including Distressed, Event-Driven, Multi-Strategy, Bonds, Convertible Arbitrage, and Merger Arbitrage, about 1\% of all pairs).

[Table 3 about here] 
Results are reported in Panel A of Table 3. We note interesting patterns in the coefficients of the network measures across strategies. First, whenever significant, social ties impact investment decisions with the expected negative sign. Of the 27 coefficients (three distance measures times three investment measures times three strategies), 22 of them are negative and 14 are significant at the $10 \%$ level or better. This implies that our results are quite robust and not driven by any single strategy. Importantly, Industry and Firm are almost always significant drivers of the distance in alphas, the sole exception being Firm for Multiprocess where the $t$-statistics is -1.61 . The strategies Security Selection and Directional Trading stay pretty close to the main results of Table 2 but lose the significance for Overlap. Multiprocess, comprising just $0.5 \%$ of the sample, loses significance for Industry and Firm for $\Delta \beta$ and $\Delta \epsilon$. It is then noteworthy that Overlap is especially relevant for Multiprocess with the largest loading of -0.706 in the case of $\Delta \epsilon$ ( $t$-statistic of -2.67$)$. We interpret the findings as evidence that Multiprocess is particularly sensitive to the sharing of information - e.g. for funds following Event-Driven, Convertible Arbitrage, and Merger Arbitrage styles. For these strategies, Overlap seems to capture word-of-mouth communications and exchange of investment ideas, which concern systematic $(\Delta \beta)$ and idiosyncratic $(\Delta \epsilon)$ risk. Industry and Firm effects seem to be less relevant for Multiprocess, except for the abnormal returns $(\Delta \alpha)$.

In addition to strategies, we next analyze whether the effect of social ties varies with fund size. Small funds are characterized by a greater proximity of key employees to the fund strategic investment decision. Thus, the effect of connected key employees is likely to be greater. We test this prediction by running our analysis separately for pairs of Small and Large funds, defined as funds below (respectively, above) the median employee size, 18. We document in Panel B of the Table 3 that the results for Small funds mimic closely the main results from Table 2 but for Overlap. Large funds lose in economic significance as coefficients are about one-third of the coefficients for Small funds for Industry and Firm. Statistical significance also suffers for Large funds. The picture is less clear for Overlap where the results, perhaps counter-intuitively, strengthen for Large funds.

\section{$5 \quad$ Testing for Alternative Hypotheses}

It is tempting to conclude that our results provide support for a causal link from social ties to hedge fund investment decisions. Establishing causality is, however, a challenging endeavor. Using 
our initial example of the commodity trading adviser AHL, we would like to argue that similarities are being driven by having been employed in the same Industry (hedge fund), at the same Firm (AHL), and possibly at the same time, Overlap. This story nicely dovetails with Simon, Millo, Kellard, and Engel (2012), who report that managers continue to discuss ideas with their former colleagues.

Yet the alternative argument could be put forward that our findings are driven by managerial characteristics. These characteristics may be personal attributes (such as, manager risk aversion) or manager innate skill. Continuing with the example above, one may argue that only skilled managers join AHL and employ similar, skilled trading strategies. Given that more skilled investors exhibit higher trading performance, see Grinblatt, Keloharju, and Linnainmaa (2012), our evidence of social ties driving abnormal returns $(\Delta \alpha)$ instead might simply measure similar managerial characteristics. This argument would imply that our estimates suffer from an endogeneity bias that leads to overestimating the impact of social ties.

We attempt to disentangle effects of social ties from those of managerial characteristics in various ways. First, we augment our regression with the following three controls that capture personal attitudes and other network-related effects: (i) the log difference in the managers' age, $\log \Delta M g r A g e$; (ii) the difference in gender, $\Delta G e n d e r$; and (iii) a dummy variable $\Delta Z$ ip that equals 1 if the two hedge fund management companies are headquartered in the same postcode district, and 0 otherwise. ${ }^{22}$

[Table 4 about here]

The results in Table 4 are organized in three panels (A, B, and $\mathrm{C}$ ) for $\Delta \alpha, \Delta \beta$, and $\Delta \epsilon$; mimicking the structure of Table 2. Models (1) in each panel of Table 4 show that the main results of Table 2 remain significant once we add managerial characteristics, although the coefficients shrink somewhat. Of the new controls, only $\Delta Z i p$ is significant for $\Delta \beta$ and $\Delta \epsilon$. The evidence that managers operating in the same postcode district exhibit correlated investment strategies is consistent with Hong, Kubik, and Stein (2005). The other two controls do not appear to be significant drivers of return distances.

\footnotetext{
${ }^{22}$ The information for $\Delta Z i p$ and $\Delta M g r A g e$ is obtained by manually looking for the manager name in the Companies House database at https://companycheck.co.uk. In the UK, filing with the Companies House is mandatory. Two postcodes are defined as being equal if they have the same outward code.
} 
Next, we strive to construct proxies for managers' skills. From an econometric viewpoint, exogenous changes in the composition of the hedge fund's managerial team (such as a manager's death) are too rare to draw any inference, and direct data on skills are unavailable for our sample. To circumvent this issue, we construct two variables that proxy for skill. The first variable is motivated by Deuskar, Pollet, Wang, and Zheng (2011)'s evidence that mutual fund managers who switch to the hedge fund industry tend to underperform relative to their peers in both the former and new employment and hence appear less skilled. Importantly, they document that these career changes are more likely to occur when the hedge fund industry is growing rapidly, which is consistent with hedge funds lowering their hiring standards during periods of extensive growth. This suggests that the 'hiring climate' might capture exogenous variation in market conditions that proxy for a fund's ability to select skilled versus unskilled managers. Following this reasoning, we define Hiring Climate as the net number of people hired in the financial industry at the time the manager was hired. We construct fund level Hiring Climate as the average of its managers' Hiring Climate. The underling assumption is that in times of great demand for money managers (Hiring Climate is high, as many managers are being newly employed), the management companies cannot be overly picky and need to hire whomever they can.

Models (2) in all panels of Table 4 add the distance in the funds' Hiring Climate as an additional control variable. Its loading has the expected positive sign across all distance measures. However, it is not statistically significant, and its inclusion does not alter the significance of our social ties measures that remain economically and statistically important. As an alternative to using Hiring Climate as a control variable, we also employ an instrumental variable approach. Namely, we first regress Industry, Firm, and Overlap on Hiring Climate and store the resulting residuals. Under the assumption that Hiring Climate captures variations in managers' skills (intelligence), the residuals in this regressions should reflect social ties among fund managers that are orthogonal to their level of skills. ${ }^{23}$ We next use these residuals in our main regression, omitting Hiring Climate from the set of controls. The results are reported in Models (3) of Table 4 and convey a similar message to those in Models (2).

In addition to Hiring Climate, we also track abnormal performance (Previous $\alpha$ ) for the subset

\footnotetext{
${ }^{23}$ Indeed, we verify that Hiring Climate negatively predicts future performance consistent with the claim that it captures some component of skill. In a panel regression of future alpha on fund controls and Hiring Climate, the latter enters with a negative coefficient and is statistically significant with a $t$-statistic of -2.50 .
} 
of managers who previously worked for a hedge fund and where we can track that hedge fund's returns in our databases. The sample size shrinks to about one-seventh of the original 1,155,000 fund-pair observations. Controlling for Previous $\alpha$ should go a long way towards absorbing skills that are innate to the manager. Models (4) in all panels of Table 4 add $\Delta$ Previous $\alpha$ to the list of regressors, which is computed as the average alpha (with respect to the 7 -factor Fung and Hsieh (2004) model) of the hedge funds the manager previously worked for (excluding the current ones). ${ }^{24}$ As we can see, $\Delta$ Previous $\alpha$ has significantly positive loadings for $\Delta \beta$ and $\Delta \epsilon$. Managers with more different Previous $\alpha$ invest in more different systematic and idiosyncratic risks, which confirms our expectation. The main results from Table 2 remain intact for Firm but weaken (and even flip the sign in Panel B) for Industry. Overall, we conclude that managerial characteristics and unobserved skills are not responsible for our main finding that social networks due to prior employment matter for similarity in investment behavior.

\section{The Economic Significance of Hedge Funds Social Ties}

Our analysis thus far uncovers proximity in the performance of hedge fund pairs due to social ties. But from an asset management perspective, it is also important to understand whether social ties ultimately impact the level of future individual hedge fund performance. In other words: Does grouping hedge funds based on the manager's prior employment background generate significant cross-sectional differences in alphas? Further, are there economic gains from loading on connected funds?

A priori, both economic and statistical arguments can be made for a link between managers' social ties and funds' performance. From an economic viewpoint, managers might learn valuable skills in the prior workplace, which allow them to make better investment decisions for the hedge fund. Being part of a specific social network might also provide valuable information sharing that improves the precision of any single manager information set. Pool, Stoffman, and Yonker (2015) provide compelling evidence that the exchange of information ultimately results in a significantly positive abnormal return. On the other hand, the evidence above that connected funds exhibit more

\footnotetext{
${ }^{24}$ If there is more than one manager for a given company, this figure is then defined as the average of the managers' previous alphas.
} 
similar return components suggests that loading on these funds may harm portfolio diversification. Moreover, correlated trades among funds of the same network may lead to the funds trading securities based on the same signals. This behavior could endogenously generate a liquidity spiral when the signal reverts, and depress their performance. Which one of these effects prevails is ultimately an empirical question.

From a statistical viewpoint, conditioning on social ties may lead to a better assessment of hedge funds' risk-return profile. It is well known that individual fund alphas tend to exhibit only modest persistence over long horizons when conditioning on past (abnormal) performance, Kosowski, Naik, and Teo (2007). Given our finding that social ties explain distances in hedge funds returns, it is natural to ask whether they could serve as valid predictors of performance. For example, finding that managers who are trained in a given industry tend to generate on average higher performance than their peers would suggest that sorting funds across this dimension is a statistically more powerful predictor of future performance than individual funds' alphas.

To investigate the economic value of hedge fund managers' networks, we conduct two complementary analyses. First, we run regressions of future fund performance on industry dummies, where these are defined based on the prior managers' working experience. That is, we construct a 'Pension Fund' dummy that equals 1 for a fund with at least one manager with prior employment in a pension fund, and 0 otherwise. Similarly, we construct dummy variables for all the 10 other industries. We include a constant term for those managers with no prior experience reported in the FSA. We focus on the effect of industry rather than company background as the number of distinct industries is much more limited, which would in turn enhance statistical power. As measures of performance we consider alpha, Sharpe ratio (excess return divided by total volatility), and Information ratio (alpha divided by residual volatility). In analogy to our pair analysis, performance is computed over the evaluation period, while the industry dummies are defined at the end of the network period.

[Table 5 about here]

Panel A of Table 5 reports the corresponding estimates for the constant, the industry dummy coefficients sorted in descending order based on alpha, and the $p$-value for the null that the dummies 
are jointly zero. We cluster the standard errors by time. The constant term for alpha is positive at 0.16, or 16 basis points per month, and highly significant. Among the industry dummies, we find that hedge funds whose managers worked at a Pension Fund and in the Banking industry deliver superior performance with respect to their peers. Alpha is more than doubled if the manager hails from the Pension Fund industry (0.26\% per month), significant at the $1 \%$ level. The effect is somewhat smaller for the Banking industry $(0.11 \%)$, significant at the $10 \%$ level. The remaining industries are insignificant but for Investment Management, where the negative effects dominate. Alpha is almost completely wiped out in that case due to a strongly significant coefficient of $-0.14 \%$. These results are consistent with expectations that a background in banking adds to performance due to social networks and skills acquired. Interestingly, the alpha for managers coming from the mutual fund industry is negative, at -3 basis points per month. This result is consistent with Deuskar, Pollet, Wang, and Zheng (2011) who find that fund managers with poor performance track records at their old mutual fund continue to underperform in the hedge fund industry. We obtain a similar (although insignificant) effect using a very different data set and time span. The null hypothesis that the industry dummies are zero is rejected with a $p$-value of 0.016 , which implies that the estimates are not simply due to random differences. The cross-sectional patterns are fairly similar when looking at the Sharpe Ratio or the Information Ratio.

Our second approach of looking at economic significance involves bootstrapped funds of funds, when these are sorted according to their degree of connectedness. ${ }^{25}$ If social networks expose managers to valuable trading ideas and investment strategies, then we expect funds of well-connected hedge funds to have higher out-of-sample performance than funds of little-connected hedge funds.

Our bootstrap procedure is as follows. Consider the first evaluation period which starts in January, 2008. Using the sample of funds available then, we randomly sample 10,000 portfolios consisting of 15 funds each. The sampling is done with replacement and is stratified to preserve the same relative style concentration as in the whole industry. ${ }^{26}$ We track each fund in the portfolio for the 3-year period ending in December, 2010 and compute the portfolio return as the

\footnotetext{
${ }^{25}$ Bootstrap methods have been widely used in prior studies as a way to improve statistical inference given the relatively recalcitrant nature of hedge fund time series, see notably Kosowski, Naik, and Teo (2007).

${ }^{26}$ For the 2008-2010 sample, this implies that the portfolios are composed of 8 funds from the Equity Long/Short category, 2 from Global Macro, 1 from Event-Driven, 1 from Fixed-Income, 1 from Emerging Markets, and 1 from Others. The stratification avoids that we erroneously pick up differences in performance across styles when sorting based on connectedness. This would arise, for example, if social ties and styles were correlated due to managers endogenously joining more popular styles.
} 
equally-weighted average of the constituent funds' returns. ${ }^{27}$ Next, we measure the level of network connectedness in the portfolio by the number of Industry connections among its funds, when these are based on the network period ending on December, 2007. To fix ideas, if only two funds in a portfolio are linked via their managers sharing a prior employment in the same industry, we assign a value of $2^{2}-2=2$. If four funds are linked, we assign a value of $4^{2}-4=12$. Based on this count, we sort the portfolios into deciles; D1 being the decile of portfolios with the lowest number of connections and D10 the decile with the highest number of connections.

We compute the alpha, Sharpe ratio, and Information ratio of each decile as the corresponding averages across the respective portfolios. We repeat this entire procedure for the other 3-year periods starting in January, 2009 and January, 2010. We report the average values across all three waves in Panel B of Table 5. We find that funds of most-connected hedge funds (portfolio D10) outperform funds of least-connected funds (D1) across all performance metrics. For alpha, funds of funds in D10 generate an abnormal return of about 0.264 compared to the 0.205 figure for D1. The difference of about 60 basis points per month is highly significant. Interestingly, the alpha increases almost monotonically as we move from D1 to D10. Analogous conclusions are drawn when considering the Sharpe ratio and the Information ratio, with D10 delivering better volatilityscaled performance than D1. Overall, these results corroborate the evidence in prior studies that network connections tend to enhance fund performance.

\section{Robustness analysis}

We conduct further analyses to verify that our results are robust to the empirical design and collect the corresponding estimates for the social ties coefficients in Table 6 .

[Table 6 about here]

First, we are concerned that our definition of distance in fund performance may be inadequate when funds use leverage. For example, it could be the case that two connected managers load on the same mix of risk factors, but only one of them levers up. Leverage would amplify the magnitude of betas and in turn their distance. To address this issue, we repeat our regressions focusing on

\footnotetext{
${ }^{27}$ If a fund drops from the sample during the 3-year period, we invest the portfolio equally in the remaining funds.
} 
fund pairs with the same leverage, as measured by our dummy variable. Results are reported in Panel A of Table 6. We note that the economic and statistical significance of our measures of connectedness is preserved. Interestingly, the effect of Overlap on $\Delta \beta$ is now significant at the $10 \%$ level. $^{28}$

Our prior analysis uses hedge funds' self-reported styles. Throughout their life, hedge fund managers may well follow strategies that deviate quite significantly from that reported style. To control for this possibility, we group funds among 10 clustered styles that are identified by their rank correlation, similar to Siegmann, Stefanova, and Zamojski (2013). We report the resulting estimates in Panel B, and they are very close to those in Table 2.

We also explore two variations of the performance-attribution model. First, we add the Pastor and Stambaugh (2003) traded liquidity factor to the set of Fung and Hsieh (2004) factors. There is evidence that hedge funds differ significantly in terms of exposure to market and funding liquidity shocks, see Jylha, Rinne, and Suominen (2014) and Franzoni and Plazzi (2014). Alternatively, we resort to the Namvar, Phillips, Pukthuanthong, and Rau (2016) 10-factor model, where factors are constructed as the first 10 principal components from a large set of asset classes. Panels C and D of Table 6 present the estimates for the two models, respectively. We draw similar conclusions to our main set of results, namely, Industry and Firm are significant determinants across all distances in return components, while Overlap matters only for the distance in idiosyncratic risk.

In Panel E, we use assets under management (AuM) in place of number of employees as a proxy for fund size. A drawback is that the number of observations is reduced by a factor of 10 to 103,000 pairs. We note that the sign of the measures of social ties remains negative, as expected. Statistical significance is, however, preserved only for Industry across all distances in performance and for Firm in the case of idiosyncratic risk (for abnormal performance, it is marginally insignificant with a $p$-value of $12 \%)$.

Finally, in Panel F we add the distance in funds' percentage flows to the set of control variables. Teo (2011) documents differences in risk-adjusted performance that are related to flows for the group of liquid funds. Including flows in the analysis shrinks our sample further to 61,000 pairs. We draw similar conclusions as in Panel E, namely, managers who share social ties display more

\footnotetext{
${ }^{28}$ In unreported results, we use measures of distance scaled by idiosyncratic volatility and obtain similar results to those in Table 2 .
} 
similar performance figures, but the evidence is weaker in statistical terms which is probably due to the smaller sample size. ${ }^{29}$

\section{Conclusion}

There is growing interest in understanding the determinants of hedge fund strategies. Much progress has been made on identifying risk factors that could explain the astonishingly large performance that hedge funds seem to be able to generate. Comparably little, however, is known about the role played by social connections in explaining differences in hedge fund returns. This study offers some steps in this direction.

Our results point towards a distinct role for social ties and work histories in explaining differences in hedge fund performance. Managers who overlap in their prior work experience at a firm are more similar in the idiosyncratic component of their hedge fund returns than non-overlapping managers. This result may be capturing the exchange of information among the managers in the network that leads to similar bets. This result seems to be driven by hedge funds betting on distressed securities, convertible securities, corporate events, and merger arbitrage - all hedge fund styles which rely on the communication of trading strategies and probability assessments among hedge fund managers. Managers having worked at the same firm or in the same (financial) industry has an economically relevant impact on all aspects of investment. Abnormal returns (alpha), systematic risks (beta), and idiosyncratic risks (epsilon) are all more similar for managers connected through Industry and Firm. As expected, smaller hedge funds, where connected managers matter more for the investment strategy, exhibit larger effects. Results are robust to numerous fund level and managerial control variables. In particular, we define hiring climate as the overall net number of hires in the financial industry. High numbers indicate on average less skilled managers as more people find jobs; low numbers mean that only the most skilled managers can secure employment. Our results survive intact when controlling for this exogenous measure of average skill.

In terms of economic significance, we find that connections within the Pension fund and the

\footnotetext{
${ }^{29}$ Another potential explanation could be that connected managers share the same investors, potentially inherited from their former common employer. This would imply that flows already capture away some of the direct effect of social connections. In an effort to test for this channel, we repeat our main analysis using distance in flows as dependent variable but cannot find a significant link with the social ties variables.
} 
Banking industry influence hedge fund alpha positively and significantly, while connections within the investment management industry reduce alpha significantly. Finally, investing in funds of most connected hedge funds and (hypothetically) shorting funds of least connected hedge funds delivers significant performance in terms of alpha, Sharpe ratio, and Information ratio. 


\section{References}

Agarwal, Vikas, Naveen D. Daniel, and Narayan Y. Naik, 2009, Role of Managerial Incentives and Discretion in Hedge Fund Performance, The Journal of Finance 64, 2221-2256.

Butler, Alexander W., and Umit G. Gurun, 2012, Educational Networks, Mutual Fund Voting Patterns, and CEO Compensation, Review of Financial Studies 25, 2533-2562.

Cohen, Lauren, Andrea Frazzini, and Christopher Malloy, 2008, The Small World of Investing: Board Connections and Mutual Fund Returns, Journal of Political Economy 116, 951-979.

— , 2010, Sell-Side School Ties, The Journal of Finance 65, 1409-1437.

Deuskar, Prachi, Joshua M. Pollet, Z. Jay Wang, and Lu Zheng, 2011, The Good or the Bad? Which Mutual Fund Managers Join Hedge Funds?, Review of Financial Studies 24, 3008-3024.

Engel, Ofer, Neil Kerllar, Yuval Millio, and Jan Simon, 2011, Dangerous Connections: Hedge Funds, Brokers and the Construction of a Market Crisis, Working Paper.

Engelberg, Joseph, Pengjie Gao, and Christopher A Parsons, 2012, Friends with Money, Journal of Financial Economics 103, 169-188.

— - 2013, The Value of a Rolodex: CEO Pay and Personal Networks, Review of Financial Studies 26, 79-114.

Fracassi, Cesare, 2015, Corporate Finance Policies and Social Networks, Management Science, forthcoming.

Franzoni, Francesco, and Alberto Plazzi, 2014, What Constrains Liquidity Provision? Evidence From Hedge Fund Trades, Working Paper, Swiss Finance Institute.

Fung, William, and David A Hsieh, 2004, Hedge Fund Benchmarks: A Risk-Based Approach, Financial Analysts Journal 60, 65-80.

Grinblatt, Mark, Matti Keloharju, and Juhani Linnainmaa, 2012, IQ, Trading Behavior, and Performance, Journal of Financial Economics 104, 339-362.

Hodder, James E., Jens Carsten Jackwerth, and Olga Kolokolova, 2014, Recovering Delisting Returns of Hedge Funds, Journal of Financial and Quantitative Analysis 49, 797-815. 
Hong, Harrison, Jeffrey D. Kubik, and Jeremy C. Stein, 2004, Social Interaction and Stock-Market Participation, The Journal of Finance 59, 137-163.

— , 2005, Thy Neighbor's Portfolio: Word-of-Mouth Effects in the Holdings and Trades of Money Managers, The Journal of Finance 60, 2801-2824.

Hwang, Byoung-Hyoun, and Seoyoung Kim, 2009, It Pays to Have Friends, Journal of Financial Economics 93, 138-158.

Ishii, Joy, and Yuhai Xuan, 2014, Acquirer-Target Social Ties and Merger Outcomes, Journal of Financial Economics 112, 344-363.

Joenvaäärä, Juha, Robert Kosowski, and Pekka Tolonen, 2014, Hedge Fund Performance: What Do We Know?, Working Paper, University of Oulu.

Jylha, Petri, Kalle Rinne, and Matti Suominen, 2014, Do Hedge Funds Supply or Demand Immediacy?, Review of Finance 18, 1259-1298.

Kosowski, Robert, Narayan Y Naik, and Melvyn Teo, 2007, Do Hedge Funds Deliver Alpha? A Bayesian and Bootstrap Analysis, Journal of Financial Economics 84, 229-264.

Lo, Andrew W., 2007, Hedge Funds: An Analytic Perspective (Princeton).

Namvar, Ethan, Blake Phillips, Kuntara Pukthuanthong, and Raghavendra Rau, 2016, Do Hedge Funds Dynamically Manage Systematic Risk?, Journal of Banking and Finance 64, 1-15.

Papageorgiou, Nicolas A, Jerry T Parwada, and Kian M Tan, 2011, Where Do Hedge Fund Managers Come from? Past Employment Connections, Performance, Survival, and Money Flows, Working Paper, Australian School of Business.

Pastor, Lubos, and Robert Stambaugh, 2003, Liquidity Risk and Expected Stock Returns, Journal of Political Economy 111, 642-685.

Patton, Andrew, and Tarun Ramadorai, 2013, On the High-frequency Dynamics of Hedge Fund Risk Exposures, The Journal of Finance 68, 597-635.

Pool, Veronika Krepely, Noah Stoffman, and Scott E. Yonker, 2015, The People in Your Neighborhood: Social Interactions and Mutual Fund Portfolio Choice, The Journal of Finance 70, $2679-2732$. 
Siegmann, Arjen, Denitsa Stefanova, and Marcin Zamojski, 2013, Hedge Fund Innovation, Working Paper, VU University Amsterdam.

Simon, Jan, Yuval Millo, Neil Kellard, and Ofer Engel, 2012, Close Connections: Hedge Funds, Brokers and the Emergence of a Consensus Trade, Working Paper, Simon Fraser University.

Teo, Melvyn, 2009, The Geography of Hedge Funds, Review of Financial Studies 22, 3531-3561.

— - 2011, The Liquidity Risk of Liquid Hedge Funds, Journal of Financial Economics 100, $24-44$. 


\section{Table 1: Dataset descriptive statistics}

For each fund in the sample, we estimate the Fung and Hsieh (2004) 7-factor model separately during the evaluation period of each wave (2008-2010, 2009-2011, and 2010-2012) to obtain idiosyncratic risk $(\epsilon)$, systematic risk $(\beta)$, and abnormal performance $(\alpha)$. Panel A reports descriptive statistics at the fund-wave level. Industry, Employer, and Overlap connection are dummy variables that equal 1 if a fund is connected through a corresponding social tie at any time. 'Adjusted $R^{2}$ ' is the adjusted $\mathrm{R}$-squared from the 7-factor model. 'Age' is the the number of months since the fund entered the database with the longest history. 'EmpSize' is the log of the number of employees of the management company. 'MgmtFee' is the fund management fee (in percentage), while 'PerfFee' is the fund performance fee (also in percentage). 'Leverage' is one if the fund employs leverage, and zero otherwise. AuM are the fund's assets under management, in USD million. Panel B reports analogous statistics at the fund pair level. $\Delta \alpha, \Delta \beta$, and $\Delta \epsilon$ denote the distances between any pair of funds belonging to two distinct management companies, as explained in Section 4.1. Industry, Firm, and Overlap are the three measures of social ties, as defined in Section 3.1 .

\begin{tabular}{|c|c|c|c|c|c|c|}
\hline \multicolumn{7}{|c|}{ Panel A: Fund-wave level dataset } \\
\hline & No obs. & Avg & Median & Std & Min & $\operatorname{Max}$ \\
\hline Industry connection & 3,516 & 0.559 & 1 & 0.497 & 0 & 1 \\
\hline Employer connection & 3,516 & 0.406 & 0 & 0.491 & 0 & 1 \\
\hline Overlap connection & 3,516 & 0.270 & 0 & 0.444 & 0 & 1 \\
\hline$\alpha$ & 3,516 & 0.144 & 0.155 & 0.932 & -5.759 & 12.917 \\
\hline Adjusted $R^{2}$ & 3,516 & 0.479 & 0.477 & 0.215 & 0.019 & 0.986 \\
\hline Age & 3,453 & 59.29 & 46 & 49.611 & 0 & 394 \\
\hline EmpSize & 2,988 & 59.89 & 18 & 220.183 & 1 & 2679 \\
\hline MgmtFee & 3,446 & 1.605 & 2 & 0.493 & 0 & 5 \\
\hline PerfFee & 3,409 & 17.44 & 20 & 5.859 & 0 & 30 \\
\hline Leverage & 1,983 & 0.309 & 0 & 0.462 & 0 & 1 \\
\hline \multirow[t]{2}{*}{$\mathrm{AuM}$} & 1,438 & 375.2 & 106.623 & 1345 & 0.019 & 31,716 \\
\hline & Equity Long/Short & Global Macro & Event-Driven & Fixed-Income & Emerging Markets & Managed Futures \\
\hline
\end{tabular}

Panel B: Pair-level dataset

\begin{tabular}{|c|c|c|c|c|c|c|}
\hline & No obs. & Avg & Median & Std & Min & Max \\
\hline$\Delta \alpha$ & $2,037,476$ & 0.877 & 0.640 & 0.847 & 0.006 & 5.229 \\
\hline$\Delta \beta$ & $2,037,476$ & 1.149 & 0.961 & 0.772 & 0.187 & 5.195 \\
\hline$\Delta \epsilon$ & $2,037,476$ & 2.977 & 2.514 & 2.002 & 0.000 & 28.531 \\
\hline Industry & $2,037,476$ & 0.222 & 0 & 0.416 & 0 & 1 \\
\hline Firm & $2,037,476$ & 0.013 & 0 & 0.115 & 0 & 1 \\
\hline Overlap & $2,037,476$ & 0.005 & 0 & 0.071 & 0 & 1 \\
\hline $\log \Delta A g e$ & $1,965,271$ & 3.553 & 3.738 & 1.076 & 0 & 5.979 \\
\hline $\log \Delta E m p$ Size & $1,466,327$ & 3.182 & 3.258 & 1.503 & 0 & 7.893 \\
\hline$\Delta$ MgmtFee & $1,957,074$ & 0.515 & 0.5 & 0.472 & 0 & 4.5 \\
\hline$\Delta$ PerfFee & $1,914,714$ & 4.701 & 0 & 6.853 & 0 & 30 \\
\hline $\log A v g E m p S i z e$ & $1,466,327$ & 3.465 & 3.401 & 0.941 & 0.693 & 7.519 \\
\hline $\log A v g A g e$ & $1,965,271$ & 3.901 & 3.998 & 0.686 & 0 & 5.862 \\
\hline $\log \Delta A u M$ & 341,107 & 18.783 & 18.786 & 1.794 & 0 & 24.180 \\
\hline
\end{tabular}




\section{Table 2: Social ties and hedge fund returns}

For each fund in the sample, we estimate the Fung and Hsieh (2004) 7-factor model separately during the evaluation period of each wave (2008-2010, 2009-2011, and 2010-2012 to obtain idiosyncratic returns $(\epsilon)$, factor loadings $(\beta)$, and abnormal performance $(\alpha)$. We then compute the average absolute distances $(\Delta \epsilon, \Delta \beta, \Delta \alpha)$ between any pair of funds belonging to two distinct management companies as explained in Section 4.1. The table reports the OLS estimates of the pooled regression of the distances on the network connection measures (Industry, Firm, and Overlap) and distances $(\Delta)$ and averages (Avg) of cross-sectional characteristics, which are defined as in Table 1. The explanatory variables are measured using information up to December 2007, 2008, and 2009 respectively. Columns (3) of all panels exclude managers with no prior FSA-regulated employment (Excl. new MGRs). Standard errors clustered along the pair level appear in parenthesis below the estimates. Statistical significance at the $1 \%, 5 \%$, and $10 \%$ level is denoted by $* * *, * *, *$ respectively.

\begin{tabular}{|c|c|c|c|c|c|c|c|c|c|}
\hline & \multicolumn{3}{|c|}{ Panel A: Distance in abnormal performance, $\Delta \alpha$} & \multicolumn{3}{|c|}{ Panel B: Distance in systematic risk, $\Delta \beta$} & \multicolumn{3}{|c|}{ Panel C: Distance in idiosyncratic risk, $\Delta \epsilon$} \\
\hline & (1) & $(2)$ & $\begin{array}{l}\text { Excl. new MGRs } \\
\text { (3) }\end{array}$ & $(1)$ & $(2)$ & $\begin{array}{l}\text { Excl. new MGRs } \\
\text { (3) }\end{array}$ & (1) & $(2)$ & $\begin{array}{l}\text { Excl. new MGRs } \\
\text { (3) }\end{array}$ \\
\hline Industry & $\begin{array}{c}-0.152^{* * *} \\
(-6.49)\end{array}$ & $\begin{array}{c}-0.104^{* * *} \\
(-4.41)\end{array}$ & $\begin{array}{c}-0.048^{* *} \\
(-2.21)\end{array}$ & $\begin{array}{c}-0.141^{* * *} \\
(-5.47)\end{array}$ & $\begin{array}{c}-0.098^{* * *} \\
(-3.98)\end{array}$ & $\begin{array}{l}-0.041 \\
(-1.17)\end{array}$ & $\begin{array}{c}-0.386^{* * *} \\
(-5.79)\end{array}$ & $\begin{array}{c}-0.238^{* * *} \\
(-3.80)\end{array}$ & $\begin{array}{l}-0.099 \\
(-1.01)\end{array}$ \\
\hline Firm & $\begin{array}{c}-0.098^{* * *} \\
(-5.97)\end{array}$ & $\begin{array}{c}-0.093^{* * *} \\
(-5.58)\end{array}$ & $\begin{array}{c}-0.097^{* * *} \\
(-6.03)\end{array}$ & $\begin{array}{c}-0.130 * * * \\
(-5.90)\end{array}$ & $\begin{array}{c}-0.107^{* * *} \\
(-4.69)\end{array}$ & $\begin{array}{c}-0.104^{* * *} \\
(-4.75)\end{array}$ & $\begin{array}{c}-0.238^{* * *} \\
(-4.74)\end{array}$ & $\begin{array}{c}-0.198^{* * * *} \\
(-3.78)\end{array}$ & $\begin{array}{c}-0.186 * * * \\
(-3.68)\end{array}$ \\
\hline Overlap & $\begin{array}{l}0.032 \\
(1.35)\end{array}$ & $\begin{array}{l}0.033 \\
(1.37)\end{array}$ & $\begin{array}{l}0.027 \\
(1.15)\end{array}$ & $\begin{array}{l}-0.016 \\
(-0.67)\end{array}$ & $\begin{array}{l}-0.022 \\
(-1.00)\end{array}$ & $\begin{array}{l}-0.030 \\
(-1.41)\end{array}$ & $\begin{array}{c}-0.140^{* * * *} \\
(-2.70)\end{array}$ & $\begin{array}{c}-0.139 * * * \\
(-2.72)\end{array}$ & $\begin{array}{c}-0.155^{* * *} \\
(-3.06)\end{array}$ \\
\hline $\log \Delta A g e$ & & $\begin{array}{l}0.004 \\
(0.67)\end{array}$ & $\begin{array}{l}-0.003 \\
(-0.57)\end{array}$ & & $\begin{array}{l}0.008 \\
(1.18)\end{array}$ & $\begin{array}{l}-0.006 \\
(-0.90)\end{array}$ & & $\begin{array}{l}-0.014 \\
(-0.85)\end{array}$ & $\begin{array}{c}-0.049 * * * \\
(-3.02)\end{array}$ \\
\hline $\log \Delta E m p S i z e$ & & $\begin{array}{c}0.017^{* *} \\
(2.21)\end{array}$ & $\begin{array}{c}0.024^{* * *} \\
(2.74)\end{array}$ & & $\begin{array}{l}-0.007 \\
(-1.14)\end{array}$ & $\begin{array}{l}0.008 \\
(1.31)\end{array}$ & & $\begin{array}{l}-0.015 \\
(-1.01)\end{array}$ & $\begin{array}{c}0.049^{* * *} \\
(3.28)\end{array}$ \\
\hline$\Delta$ MgmtFee & & $\begin{array}{l}0.000 \\
(0.00)\end{array}$ & $\begin{array}{c}-0.035^{*} \\
(-1.95)\end{array}$ & & $\begin{array}{l}-0.011 \\
(-0.51)\end{array}$ & $\begin{array}{l}-0.009 \\
(-0.39)\end{array}$ & & $\begin{array}{l}-0.079 \\
(-1.58)\end{array}$ & $\begin{array}{l}-0.046 \\
(-1.05)\end{array}$ \\
\hline$\Delta$ PerfFee & & $\begin{array}{l}0.001 \\
(0.73)\end{array}$ & $\begin{array}{l}0.000 \\
(0.13)\end{array}$ & & $\begin{array}{c}0.006^{* * *} \\
(3.02)\end{array}$ & $\begin{array}{c}0.004^{* *} \\
(2.01)\end{array}$ & & $\begin{array}{l}0.001 \\
(0.29)\end{array}$ & $\begin{array}{l}-0.006 \\
(-1.59)\end{array}$ \\
\hline $\log$ AvgEmpSize & & $\begin{array}{c}-0.094^{* * *} \\
(-4.42)\end{array}$ & $\begin{array}{c}-0.075^{* * *} \\
(-3.01)\end{array}$ & & $\begin{array}{c}-0.077^{* * *} \\
(-5.16)\end{array}$ & $\begin{array}{c}-0.084^{* * *} \\
(-4.64)\end{array}$ & & $\begin{array}{c}-0.221^{* * * *} \\
(-5.98)\end{array}$ & $\begin{array}{c}-0.281 * * * \\
(-6.02)\end{array}$ \\
\hline $\log A v g A g e$ & & $\begin{array}{c}-0.043^{* *} \\
(-2.10)\end{array}$ & $\begin{array}{l}-0.003 \\
(-0.18)\end{array}$ & & $\begin{array}{c}-0.080^{* * *} \\
(-3.36)\end{array}$ & $\begin{array}{l}-0.026 \\
(-1.19)\end{array}$ & & $\begin{array}{c}-0.114^{*} \\
(-1.88)\end{array}$ & $\begin{array}{l}0.033 \\
(0.62)\end{array}$ \\
\hline Style Dummy & $\begin{array}{c}-0.038^{*} \\
(-1.90)\end{array}$ & $\begin{array}{l}-0.025 \\
(-1.15)\end{array}$ & $\begin{array}{l}-0.027 \\
(-1.16)\end{array}$ & $\begin{array}{l}-0.003 \\
(-0.16)\end{array}$ & $\begin{array}{l}0.017 \\
(0.84)\end{array}$ & $\begin{array}{l}-0.015 \\
(-0.61)\end{array}$ & $\begin{array}{l}0.087 \\
(1.57)\end{array}$ & $\begin{array}{l}0.104^{*} \\
(1.84)\end{array}$ & $\begin{array}{l}0.003 \\
(0.05)\end{array}$ \\
\hline Time FE & Yes & Yes & Yes & Yes & Yes & Yes & Yes & Yes & Yes \\
\hline Obs. ('000) & 2,037 & 1,301 & 513 & 2,037 & 1,301 & 513 & 2,037 & 1,301 & 513 \\
\hline Adj. R-squared & 0.011 & 0.02 & 0.014 & 0.007 & 0.026 & 0.017 & 0.031 & 0.055 & 0.064 \\
\hline
\end{tabular}




\section{Table 3: Social ties and hedge fund returns, subsample analysis}

For each fund in the sample, we estimate the Fung and Hsieh (2004) 7 -factor model separately during the evaluation period of each wave (2008-2010, 2009-2011, and 2010-2012) to obtain idiosyncratic risk $(\epsilon)$, systematic risk $(\beta)$, and abnormal performance $(\alpha)$. We then compute the average absolute distances $(\Delta \epsilon, \Delta \beta, \Delta \alpha)$ between any pair of funds belonging to two distinct management companies as explained in Section 4.1. The table reports the OLS estimates of the pooled regression of the distances on the network connection measures (Industry, Firm, and Overlap) and distances $(\Delta)$ and averages (Avg) of crosssectional characteristics, which are defined as in Table 1 . The explanatory variables are measured using information up to December 2007, 2008, and 2009 respectively. In Panel A, the regression is estimated separately on the sample of fund pairs whose styles fall into the Security Selection, Directional Traders, or Multiprocess and Relative Value investment strategies. In Panel B, the regression is estimated separately on the sample of fund pairs where both funds are Small $($ EmpSize < 18) or Large (EmpSize $\geq 18)$. The coefficients on the cross-sectional controls, time fixed effects, and style dummy are omitted to save space. Standard errors clustered along the pair level appear in parenthesis below the estimates. Statistical significance at the $1 \%, 5 \%$, and $10 \%$ level is denoted by $* * *, * *, *$ respectively.

Panel A: By investment strategy

\begin{tabular}{|c|c|c|c|c|c|c|c|c|c|}
\hline & \multicolumn{3}{|c|}{ Security Selection } & \multicolumn{3}{|c|}{ Directional Traders } & \multicolumn{3}{|c|}{ Multiprocess and Relative Value } \\
\hline & $\Delta \alpha$ & $\Delta \beta$ & $\Delta \epsilon$ & $\Delta \alpha$ & $\Delta \beta$ & $\Delta \epsilon$ & $\Delta \alpha$ & $\Delta \beta$ & $\Delta \epsilon$ \\
\hline Industry & $\begin{array}{c}-0.084^{* * *} \\
(-2.66)\end{array}$ & $\begin{array}{c}-0.165^{* * *} \\
(-4.58)\end{array}$ & $\begin{array}{c}-0.436^{* * *} \\
(-4.61)\end{array}$ & $\begin{array}{c}-0.139 * * \\
(-2.18)\end{array}$ & $\begin{array}{c}-0.098^{*} \\
(-1.95)\end{array}$ & $\begin{array}{c}-0.219^{*} \\
(-1.79)\end{array}$ & $\begin{array}{c}-0.208^{* * *} \\
(-3.30)\end{array}$ & $\begin{array}{l}-0.030 \\
(-0.60)\end{array}$ & $\begin{array}{l}-0.213 \\
(-1.60)\end{array}$ \\
\hline Firm & $\begin{array}{c}-0.079 * * * \\
(-3.08)\end{array}$ & $\begin{array}{c}-0.060 * * \\
(-2.55)\end{array}$ & $\begin{array}{l}-0.059 \\
(-1.04)\end{array}$ & $\begin{array}{c}-0.149^{* *} \\
(-2.44)\end{array}$ & $\begin{array}{c}-0.229 * * * \\
(-4.10)\end{array}$ & $\begin{array}{c}-0.354^{* *} \\
(-2.23)\end{array}$ & $\begin{array}{l}-0.104 \\
(-1.61)\end{array}$ & $\begin{array}{l}0.074 \\
(0.64)\end{array}$ & $\begin{array}{l}0.204 \\
(0.74)\end{array}$ \\
\hline Overlap & $\begin{array}{l}0.048 \\
(1.37)\end{array}$ & $\begin{array}{l}-0.012 \\
(-0.37)\end{array}$ & $\begin{array}{l}-0.115 \\
(-1.50)\end{array}$ & $\begin{array}{l}-0.022 \\
(-0.29)\end{array}$ & $\begin{array}{l}0.035 \\
(0.49)\end{array}$ & $\begin{array}{l}-0.091 \\
(-0.43)\end{array}$ & $\begin{array}{l}0.093 \\
(0.79)\end{array}$ & $\begin{array}{c}-0.390 * * * \\
(-3.36)\end{array}$ & $\begin{array}{c}-0.706^{* * *} \\
(-2.67)\end{array}$ \\
\hline Fund controls & Yes & Yes & Yes & Yes & Yes & Yes & Yes & Yes & Yes \\
\hline Time FE & Yes & Yes & Yes & Yes & Yes & Yes & Yes & Yes & Yes \\
\hline Obs. ('000) & 296 & 296 & 296 & 33 & 33 & 33 & 11 & 11 & 11 \\
\hline Adj. R-squared & 0.025 & 0.066 & 0.081 & 0.053 & 0.031 & 0.062 & 0.020 & 0.019 & 0.048 \\
\hline
\end{tabular}

Panel B: By fund size

\begin{tabular}{|c|c|c|c|c|c|c|}
\hline & \multicolumn{3}{|c|}{ Small funds } & \multicolumn{3}{|c|}{ Large funds } \\
\hline & $\Delta \alpha$ & $\Delta \beta$ & $\Delta \epsilon$ & $\Delta \alpha$ & $\Delta \beta$ & $\Delta \epsilon$ \\
\hline Industry & $\begin{array}{c}-0.109^{* *} \\
(-2.28)\end{array}$ & $\begin{array}{c}-0.173^{* * *} \\
(-4.06)\end{array}$ & $\begin{array}{c}-0.388^{* * *} \\
(-3.39)\end{array}$ & $\begin{array}{c}-0.056^{* *} \\
(-2.01)\end{array}$ & $\begin{array}{l}-0.044 \\
(-1.52)\end{array}$ & $\begin{array}{l}-0.100 \\
(-1.62)\end{array}$ \\
\hline Firm & $\begin{array}{c}-0.269^{* * *} \\
(-4.68)\end{array}$ & $\begin{array}{c}-0.187^{*} * * \\
(-3.01)\end{array}$ & $\begin{array}{c}-0.608^{* * * *} \\
(-4.02)\end{array}$ & $\begin{array}{c}-0.074^{* * *} * \\
(-4.26)\end{array}$ & $\begin{array}{c}-0.096^{* * *} \\
(-3.78)\end{array}$ & $\begin{array}{c}-0.106^{*} \\
(-1.85)\end{array}$ \\
\hline Overlap & $\begin{array}{l}0.007 \\
(0.08)\end{array}$ & $\begin{array}{l}-0.012 \\
(-0.15)\end{array}$ & $\begin{array}{l}-0.068 \\
(-0.34)\end{array}$ & $\begin{array}{l}0.045^{*} \\
(1.66)\end{array}$ & $\begin{array}{l}-0.005 \\
(-0.21)\end{array}$ & $\begin{array}{c}-0.124^{* *} \\
(-2.12)\end{array}$ \\
\hline Fund controls & Yes & Yes & Yes & Yes & Yes & Yes \\
\hline Time FE & Yes & Yes & Yes & Yes & Yes & Yes \\
\hline Obs. ('000) & 308 & 308 & 308 & 333 & 333 & 333 \\
\hline Adj. R-squared & 0.020 & 0.016 & 0.037 & 0.010 & 0.030 & 0.060 \\
\hline
\end{tabular}


Table 4: Social ties and hedge fund returns, testing for alternative hypotheses

For each fund in the sample, we estimate the Fung and Hsieh (2004) 7-factor model separately during the evaluation period of each wave (2008-2010, 2009-2011, and 2010-2012 to obtain idiosyncratic risk $(\epsilon)$, systematic risk $(\beta)$, and abnormal performance $(\alpha)$. We then compute the average absolute distances $(\Delta \epsilon, \Delta \beta, \Delta \alpha)$ between any pair of funds belonging to two distinct management companies as explained in Section 4.1. The table reports the OLS estimates of the pooled regression of the distances on: the connection measures (Industry, Firm, and Overlap); distances $(\Delta)$ and averages (Avg) of cross-sectional characteristics, which are defined as in Table 1; a dummy that equals 1 if the two companies are headquartered in the same postcode district and 0 otherwise, $\Delta Z i p$; the log distance in managers' age, $\log \Delta M g r A g e ;$ the distance in gender, $\Delta G e n d e r$, with 0 being of same gender and 1 otherwise; the distance in hiring climate, $\Delta$ Hiring Climate, constructed as explained in Section 5 ; the distance in the managers' previous alpha, $\Delta$ Previous $\alpha$, for the managers with prior employment in the hedge fund industry. The column 'IV' denotes the instrumental variable approach that uses the residuals from regressing the connection measures on $\Delta$ Hiring Climate. The explanatory variables are measured using information up to December 2007,2008 , and 2009 respectively. The coefficients on the cross-sectional controls, time fixed effects, and style dummy are omitted to save space. Standard errors clustered along the pair level appear in parenthesis below the estimates. Statistical significance at the $1 \%, 5 \%$, and $10 \%$ level is denoted by $* * *, * *, *$ respectively.

\begin{tabular}{|c|c|c|c|c|c|c|c|c|c|c|c|c|}
\hline & \multicolumn{4}{|c|}{$\begin{array}{c}\text { Panel A: Distance in abnormal performance, } \Delta \alpha \\
\text { IV }\end{array}$} & \multicolumn{4}{|c|}{$\begin{array}{c}\text { Panel B: Distance in systematic risk, } \Delta \beta \\
\text { IV }\end{array}$} & \multicolumn{4}{|c|}{ Panel C: Distance in idiosyncratic risk, $\Delta \epsilon$} \\
\hline & (1) & $(2)$ & (3) & (4) & $(1)$ & (2) & (3) & (4) & $(1)$ & $(2)$ & $(3)$ & (4) \\
\hline Industry & $\begin{array}{c}-0.091 * * * \\
(-3.83)\end{array}$ & $\begin{array}{c}-0.102^{* * *} \\
(-4.01)\end{array}$ & $\begin{array}{c}-0.101^{* * *} \\
(-3.96)\end{array}$ & $\begin{array}{l}0.039 \\
(0.84)\end{array}$ & $\begin{array}{c}-0.098^{* * *} \\
(-3.89)\end{array}$ & $\begin{array}{c}-0.091 * * * \\
(-3.43)\end{array}$ & $\begin{array}{c}-0.090^{* * *} \\
(-3.37)\end{array}$ & $\begin{array}{c}0.091^{* *} \\
(2.47)\end{array}$ & $\begin{array}{c}-0.231^{* * *} \\
(-3.69)\end{array}$ & $\begin{array}{c}-0.237^{* * *} \\
(-3.58)\end{array}$ & $\begin{array}{c}-0.226^{* * *} \\
(-3.44)\end{array}$ & $\begin{array}{c}0.128^{*} \\
(1.70)\end{array}$ \\
\hline Firm & $\begin{array}{c}-0.096^{* * *} \\
(-5.82)\end{array}$ & $\begin{array}{c}-0.092^{* * *} \\
(-5.88)\end{array}$ & $\begin{array}{c}-0.092^{* * *} \\
(-5.82)\end{array}$ & $\begin{array}{c}-0.120^{* * *} \\
(-6.17)\end{array}$ & $\begin{array}{c}-0.108^{* * *} \\
(-4.74)\end{array}$ & $\begin{array}{c}-0.103^{* * *} \\
(-4.65)\end{array}$ & $\begin{array}{c}-0.102^{* * *} \\
(-4.60)\end{array}$ & $\begin{array}{c}-0.141^{* * *} \\
(-5.37)\end{array}$ & $\begin{array}{c}-0.204^{* * *} \\
(-3.87)\end{array}$ & $\begin{array}{c}-0.175^{* * *} \\
(-3.40)\end{array}$ & $\begin{array}{c}-0.172^{* * *} \\
(-3.30)\end{array}$ & $\begin{array}{c}-0.246^{* * *} \\
(-3.87)\end{array}$ \\
\hline Overlap & $\begin{array}{l}0.041 \\
(1.50)\end{array}$ & $\begin{array}{l}0.035 \\
(1.22)\end{array}$ & $\begin{array}{l}0.036 \\
(1.25)\end{array}$ & $\begin{array}{c}0.073^{* * *} \\
(2.84)\end{array}$ & $\begin{array}{l}-0.000 \\
(-0.00)\end{array}$ & $\begin{array}{l}-0.004 \\
(-0.16)\end{array}$ & $\begin{array}{l}-0.003 \\
(-0.13)\end{array}$ & $\begin{array}{l}0.017 \\
(0.75)\end{array}$ & $\begin{array}{l}-0.074 \\
(-1.33)\end{array}$ & $\begin{array}{c}-0.103^{*} \\
(-1.78)\end{array}$ & $\begin{array}{c}-0.098^{*} \\
(-1.75)\end{array}$ & $\begin{array}{c}0.009 \\
(0.16)\end{array}$ \\
\hline$\Delta Z i p$ & $\begin{array}{l}0.028 \\
(0.67)\end{array}$ & $\begin{array}{l}0.025 \\
(0.57)\end{array}$ & $\begin{array}{l}0.027 \\
(0.60)\end{array}$ & $\begin{array}{c}0.075^{*} \\
(1.86)\end{array}$ & $\begin{array}{c}0.156^{* * *} \\
(4.37)\end{array}$ & $\begin{array}{c}0.142^{* * *} \\
(3.90)\end{array}$ & $\begin{array}{c}0.144^{* * *} * \\
(3.95)\end{array}$ & $\begin{array}{c}0.097^{* *} \\
(2.22)\end{array}$ & $\begin{array}{c}0.437^{* * *} \\
(4.41)\end{array}$ & $\begin{array}{c}0.417^{* * *} \\
(4.09)\end{array}$ & $\begin{array}{c}0.426^{* * *} \\
(4.13)\end{array}$ & $\begin{array}{c}0.183^{*} \\
(1.93)\end{array}$ \\
\hline $\log \Delta M g r A g e$ & $\begin{array}{l}-0.009 \\
(-1.14)\end{array}$ & $\begin{array}{c}-0.018^{* * *} \\
(-3.17)\end{array}$ & $\begin{array}{c}-0.017^{* * *} \\
(-3.12)\end{array}$ & $\begin{array}{l}-0.008 \\
(-1.04)\end{array}$ & $\begin{array}{l}0.000 \\
(0.06)\end{array}$ & $\begin{array}{l}-0.003 \\
(-0.34)\end{array}$ & $\begin{array}{l}-0.002 \\
(-0.23)\end{array}$ & $\begin{array}{l}0.003 \\
(0.41)\end{array}$ & $\begin{array}{l}-0.013 \\
(-0.58)\end{array}$ & $\begin{array}{c}-0.034^{*} \\
(-1.70)\end{array}$ & $\begin{array}{l}-0.029 \\
(-1.52)\end{array}$ & $\begin{array}{l}-0.018 \\
(-1.01)\end{array}$ \\
\hline$\Delta$ Gender & $\begin{array}{l}0.041 \\
(0.68)\end{array}$ & $\begin{array}{l}0.103 \\
(1.60)\end{array}$ & $\begin{array}{c}0.098 \\
(1.53)\end{array}$ & $\begin{array}{l}0.018 \\
(0.22)\end{array}$ & $\begin{array}{l}0.058 \\
(0.77)\end{array}$ & $\begin{array}{l}0.151^{*} \\
(1.77)\end{array}$ & $\begin{array}{l}0.145^{*} \\
(1.70)\end{array}$ & $\begin{array}{l}0.090 \\
(0.81)\end{array}$ & $\begin{array}{l}-0.137 \\
(-0.88)\end{array}$ & $\begin{array}{l}0.050 \\
(0.30)\end{array}$ & $\begin{array}{l}0.015 \\
(0.09)\end{array}$ & $\begin{array}{l}0.026 \\
(0.12)\end{array}$ \\
\hline$\Delta$ Hiring Climate & & $\begin{array}{l}0.032 \\
(0.74)\end{array}$ & & $\begin{array}{l}-0.075 \\
(-0.86)\end{array}$ & & $\begin{array}{l}0.041 \\
(0.90)\end{array}$ & & $\begin{array}{l}-0.070 \\
(-0.92)\end{array}$ & & $\begin{array}{l}0.277 \\
(1.55)\end{array}$ & & $\begin{array}{l}-0.249 \\
(-1.13)\end{array}$ \\
\hline$\Delta$ Previous $\alpha$ & & & & $\begin{array}{l}-0.030 \\
(-1.05)\end{array}$ & & & & $\begin{array}{c}0.103^{* *} \\
(2.53)\end{array}$ & & & & $\begin{array}{c}0.131^{*} \\
(1.77)\end{array}$ \\
\hline Fund controls & Yes & Yes & Yes & Yes & Yes & Yes & Yes & Yes & Yes & Yes & Yes & Yes \\
\hline Time FE & Yes & Yes & Yes & Yes & Yes & Yes & Yes & Yes & Yes & Yes & Yes & Yes \\
\hline Obs. ('000) & 1,155 & 942 & 942 & 156 & 1,155 & 942 & 942 & 156 & 1,155 & 942 & 942 & 156 \\
\hline Adj. R-squared & 0.019 & 0.021 & 0.02 & 0.014 & 0.027 & 0.026 & 0.025 & 0.023 & 0.055 & 0.061 & 0.055 & 0.07 \\
\hline
\end{tabular}




\section{Table 5: Economic significance of hedge funds social ties}

Panel A reports the estimates from the panel regression of a fund's Alpha, Sharpe Ratio, or Information Ratio on the manager's Industry. The last row reports the $p$-value for the F-test that all coefficients (excluding the constant) are zero. Panel B reports the Alpha, Sharpe Ratio, and Information Ratio for portfolios of hedge funds that are sorted into deciles according to the degree of Industry connectedness. The portfolios are formed using the bootstrap procedure described in Section 6 . The last two rows report the statistics for a strategy that goes long portfolio D10 and short portfolio D1, along with its $p$-value. We cluster the standard errors by time.

Panel A: Past industry and future performance

\begin{tabular}{lccc} 
& Alpha & Sharpe Ratio & Information Ratio \\
\hline Constant & $0.160^{* * *}$ & $0.166^{* * *}$ & $0.110^{* * *}$ \\
Pension Fund & $0.255^{* * *}$ & $0.070^{* *}$ & $0.110^{* * *}$ \\
Bank & $0.110^{*}$ & $0.033^{*}$ & $0.056^{* *}$ \\
Other & 0.069 & 0.011 & 0.035 \\
Brokerage & 0.046 & -0.034 & 0.004 \\
Private Equity & 0.039 & 0.006 & 0.036 \\
Investment Bank & 0.034 & -0.002 & 0.038 \\
Hedge Fund & 0.031 & -0.002 & 0.000 \\
Consultancy & -0.006 & 0.028 & -0.01 \\
Mutual Fund & -0.027 & 0.004 & -0.012 \\
Insurance & -0.048 & 0.003 & 0.028 \\
Investment Management & $-0.144^{* * *}$ & $-0.047^{* * *}$ & $-0.080^{* * *}$ \\
Obs. & & & 3,513 \\
$p$-value F-test & 3,513 & 3,513 & 0.001
\end{tabular}

Panel B: Loading on industry connection, bootstrap results

\begin{tabular}{lccc} 
Industry connectedness deciles & Alpha & Sharpe Ratio & Information Ratio \\
\hline D1=Low & 0.205 & 0.656 & 0.126 \\
D2 & 0.222 & 0.666 & 0.141 \\
D3 & 0.230 & 0.665 & 0.151 \\
D4 & 0.244 & 0.681 & 0.157 \\
D5 & 0.239 & 0.690 & 0.161 \\
D6 & 0.241 & 0.709 & 0.165 \\
D7 & 0.239 & 0.687 & 0.165 \\
D8 & 0.265 & 0.719 & 0.188 \\
D9 & 0.251 & 0.721 & 0.179 \\
D10=High & 0.264 & 0.734 & 0.193 \\
& & & 0.067 \\
D10-D1 & 0.059 & 0.078 & $<0.001$ \\
$p$-value & $<0.001$ & $<0.001$ & \\
\hline \hline
\end{tabular}




\section{Table 6: Social ties and hedge fund returns, robustness analysis}

The Table shows six alternative specifications of model (2) in Table 2. In Panel A, we restrict the sample to funds with the same amount of leverage. In Panel B, the style dummy is defined with respect to 10 clustered styles based on rank correlation, rather than self-reported styles. In Panel $\mathrm{C}$ and $\mathrm{D}$ we use two alternative models to decompose funds returns. In Panel C, we augment the Fung and Hsieh (2004) 7-factor model with the traded liquidity factor of Pastor and Stambaugh (2003). In Panel D, we instead use the 10-factor model of Namvar, Phillips, Pukthuanthong, and Rau (2016). In Panel E we use assets under management instead of employee size as control variable. In Panel $\mathrm{F}$ we add the distance in fund flows to the set of controls. The coefficients on the cross-sectional controls, time fixed effects, and style dummy are omitted to save space. Standard errors clustered along the pair level appear in parenthesis below the estimates. Statistical significance at the 1\%, $5 \%$, and $10 \%$ level is denoted by $* * *, * *, *$ respectively.

\begin{tabular}{|c|c|c|c|c|c|c|}
\hline & \multicolumn{3}{|c|}{ Panel A: Funds with same leverage } & \multicolumn{3}{|c|}{ Panel B: Clustered-based styles } \\
\hline & $\Delta \alpha$ & $\Delta \beta$ & $\Delta \epsilon$ & $\Delta \alpha$ & $\Delta \beta$ & $\Delta \epsilon$ \\
\hline Industry & $\begin{array}{c}-0.104 * * * \\
(-4.31)\end{array}$ & $\begin{array}{c}-0.103 * * * \\
(-4.09)\end{array}$ & $\begin{array}{c}-0.262^{* * *} \\
(-4.12)\end{array}$ & $\begin{array}{c}-0.104^{* * *} \\
(-4.44)\end{array}$ & $\begin{array}{c}-0.097 * * * \\
(-3.98)\end{array}$ & $\begin{array}{c}-0.232^{* * *} \\
(-3.75)\end{array}$ \\
\hline Firm & $\begin{array}{c}-0.068^{* * *} \\
(-3.47)\end{array}$ & $\begin{array}{c}-0.078^{* * *} \\
(-3.16)\end{array}$ & $\begin{array}{c}-0.159^{* * *} \\
(-2.93)\end{array}$ & $\begin{array}{c}-0.094^{* * *} \\
(-5.60)\end{array}$ & $\begin{array}{c}-0.106^{* * *} \\
(-4.67)\end{array}$ & $\begin{array}{c}-0.196^{* * *} \\
(-3.72)\end{array}$ \\
\hline Overlap & $\begin{array}{l}0.014 \\
(0.45)\end{array}$ & $\begin{array}{c}-0.045^{*} \\
(-1.81)\end{array}$ & $\begin{array}{c}-0.144^{* *} \\
(-2.42)\end{array}$ & $\begin{array}{c}0.034 \\
(1.38)\end{array}$ & $\begin{array}{l}-0.022 \\
(-0.99)\end{array}$ & $\begin{array}{c}-0.137 * * * \\
(-2.65)\end{array}$ \\
\hline Fund controls & Yes & Yes & Yes & Yes & Yes & Yes \\
\hline Time FE & Yes & Yes & Yes & Yes & Yes & Yes \\
\hline Obs. ('000) & 474 & 474 & 474 & 1,301 & 1,301 & 1,301 \\
\hline \multirow[t]{3}{*}{ Adj. R-squared } & 0.022 & 0.033 & 0.061 & 0.02 & 0.026 & 0.054 \\
\hline & \multicolumn{3}{|c|}{ Panel C: Adding Liquidity Factor } & \multicolumn{3}{|c|}{ Panel D: NPPR 10-factor model } \\
\hline & $\Delta \alpha$ & $\Delta \beta$ & $\Delta \epsilon$ & $\Delta \alpha$ & $\Delta \beta$ & $\Delta \epsilon$ \\
\hline Industry & $\begin{array}{c}-0.090^{* * *} \\
(-4.07)\end{array}$ & $\begin{array}{c}-0.083^{* * *} \\
(-3.58)\end{array}$ & $\begin{array}{c}-0.237^{* * *} \\
(-3.94)\end{array}$ & $\begin{array}{c}-0.098^{* * *} \\
(-4.63)\end{array}$ & $\begin{array}{c}-0.064^{* * *} \\
(-3.27)\end{array}$ & $\begin{array}{c}-0.224^{* * *} \\
(-3.91)\end{array}$ \\
\hline Firm & $\begin{array}{c}-0.089 * * * \\
(-5.26)\end{array}$ & $\begin{array}{c}-0.106^{* * * *} \\
(-4.88)\end{array}$ & $\begin{array}{c}-0.182^{* * *} \\
(-3.62)\end{array}$ & $\begin{array}{c}-0.060^{* * * *} \\
(-2.97)\end{array}$ & $\begin{array}{c}-0.100 * * * \\
(-4.26)\end{array}$ & $\begin{array}{c}-0.184 * * * \\
(-3.76)\end{array}$ \\
\hline Overlap & $\begin{array}{l}0.025 \\
(1.00)\end{array}$ & $\begin{array}{l}-0.024 \\
(-1.19)\end{array}$ & $\begin{array}{c}-0.128^{* *} \\
(-2.56)\end{array}$ & $\begin{array}{l}-0.020 \\
(-0.81)\end{array}$ & $\begin{array}{l}-0.031 \\
(-1.59)\end{array}$ & $\begin{array}{c}-0.106^{* *} \\
(-2.22)\end{array}$ \\
\hline Fund controls & Yes & Yes & Yes & Yes & Yes & Yes \\
\hline Time FE & Yes & Yes & Yes & Yes & Yes & Yes \\
\hline Obs. ('000) & 1,301 & 1,301 & 1,301 & 1,301 & 1,301 & 1,301 \\
\hline \multirow[t]{2}{*}{ Adj. R-squared } & 0.022 & 0.026 & 0.057 & 0.032 & 0.049 & 0.061 \\
\hline & \multicolumn{3}{|c|}{ Panel E: Controlling for AuM } & \multicolumn{3}{|c|}{ Panel D: Controlling for Flows } \\
\hline Industry & $\begin{array}{c}-0.256^{* * *} \\
(-6.02)\end{array}$ & $\begin{array}{c}-0.202^{* * *} \\
(-4.72)\end{array}$ & $\begin{array}{c}-0.588^{* * *} \\
(-4.77)\end{array}$ & $\begin{array}{c}-0.187^{* * *} \\
(-4.26)\end{array}$ & $\begin{array}{c}-0.141^{* * *} \\
(-3.60)\end{array}$ & $\begin{array}{c}-0.419^{* * *} \\
(-3.74)\end{array}$ \\
\hline Firm & $\begin{array}{l}-0.060 \\
(-1.57)\end{array}$ & $\begin{array}{l}-0.033 \\
(-0.67)\end{array}$ & $\begin{array}{c}-0.247^{* *} \\
(-2.42)\end{array}$ & $\begin{array}{l}-0.068 \\
(-1.64)\end{array}$ & $\begin{array}{l}-0.006 \\
(-0.10)\end{array}$ & $\begin{array}{c}-0.249^{* *} \\
(-2.01)\end{array}$ \\
\hline Overlap & $\begin{array}{l}0.042 \\
(0.88)\end{array}$ & $\begin{array}{l}-0.023 \\
(-0.44)\end{array}$ & $\begin{array}{l}-0.050 \\
(-0.50)\end{array}$ & $\begin{array}{l}0.041 \\
(0.76)\end{array}$ & $\begin{array}{l}-0.064 \\
(-0.99)\end{array}$ & $\begin{array}{l}-0.006 \\
(-0.05)\end{array}$ \\
\hline Fund controls & Yes & Yes & Yes & Yes & Yes & Yes \\
\hline Time FE & Yes & Yes & Yes & Yes & Yes & Yes \\
\hline Obs. ('000) & 103 & 103 & 103 & 61 & 61 & 61 \\
\hline Adj. R-squared & 0.032 & 0.050 & 0.062 & 0.035 & 0.034 & 0.057 \\
\hline
\end{tabular}


Table A1: Hedge Fund Data Representativeness

This table reports the regression of funds characteristics of the universe of hedge funds on a constant and an 'FSA' dummy for funds in the combined FSA data set that is used in our study. Variables definition follows from Table 1. 'Alive' is a dummy for funds that are alive by the end of the period. In parenthesis, we report $t$-statistics based on standard errors clustered on the level of the style and the managing company.

\begin{tabular}{lcccccc}
\hline \hline & & MgmtFee & PerfFree & Age & Leverage & Aum \\
& $(1)$ & $(2)$ & $(3)$ & $(5)$ & $\begin{array}{c}\text { Alive } \\
(6)\end{array}$ \\
\hline Constant & $1.545^{* * *}$ & $18.170^{* * *}$ & $106.399^{* * *}$ & $0.373^{* * *}$ & 460.771 & $0.665^{* * *}$ \\
& $(47.53)$ & $(65.45)$ & $(51.51)$ & $(14.77)$ & $(2.53)$ & $(39.09)$ \\
FSA & 0.046 & $-0.819^{*}$ & $-6.824^{* *}$ & -0.057 & -119.512 & -0.006 \\
& $(1.17)$ & $(-1.95)$ & $(-2.46)$ & $(-1.47)$ & $(-0.54)$ & $(-0.20)$ \\
Obs. & 7,199 & 7,175 & 7,470 & 4,358 & 4,407 & 4,247 \\
R-squared & 0.001 & 0.003 & 0.002 & 0.002 & 0.000 & 0.000 \\
& & & & & & \\
\hline \hline
\end{tabular}




\section{Figure A1: Distribution of Prior Industries and Employers}

Panel A displays the distribution of the number of managers by former employer industry, while Panel B displays the distribution of managers for the top-10 former employers in the data set.

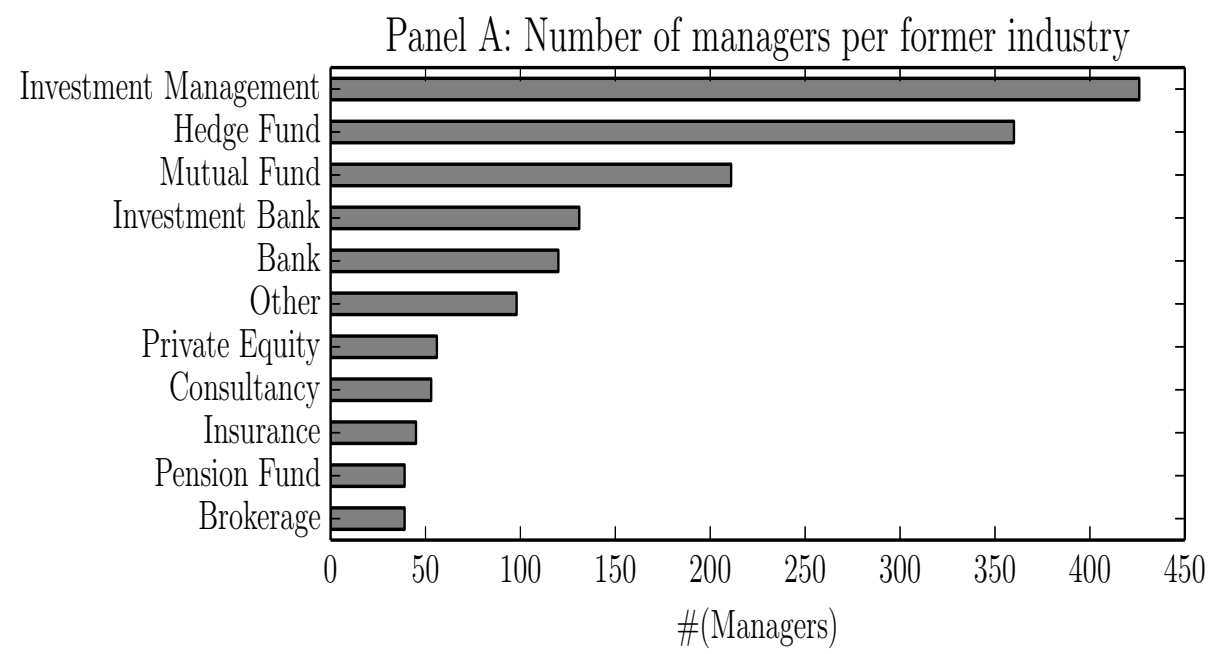

Panel B: Number of managers per former employer

Cheyne Capital Management

Brevan Howard

Goldman Sachs

JPMorgan Chase Bank

J.P. Morgan Securities

Thames River Capital

Cheyne Capital Management

Credit Suisse Securities

Morgan Stanley \& Co.

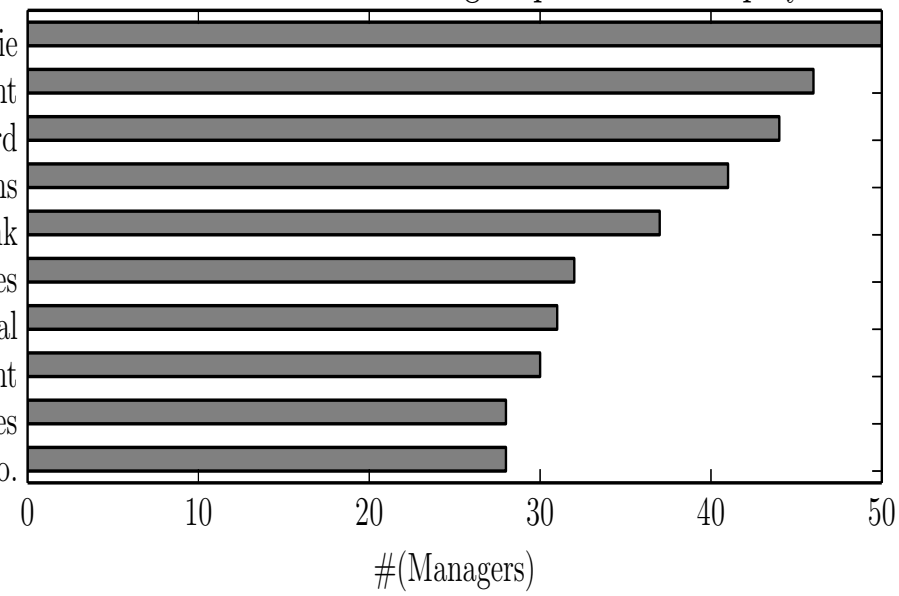

